Article

\title{
The Impact of Vegetation on Lithological Mapping Using Airborne Multispectral Data: A Case Study for the North Troodos Region, Cyprus
}

\section{Stephen Grebby ${ }^{1, *}$, Dickson Cunningham ${ }^{2}$, Kevin Tansey ${ }^{3}$ and Jonathan Naden ${ }^{1}$}

1 British Geological Survey, Keyworth, Nottingham NG12 5GG, UK; E-Mail: jna@nigl.nerc.ac.uk

2 Department of Environmental Earth Science, Eastern Connecticut State University, Willimantic, CT 06226, USA; E-Mail: cunninghamw@easternct.edu

3 Department of Geography, University of Leicester, University Road, Leicester LE1 7RH, UK; E-Mail:kjt7@leicester.ac.uk

* Author to whom correspondence should be addressed; E-Mail: stgrebby@bgs.ac.uk; Tel.: +44-115-936-3148; Fax: +44-115-936-3446.

External Editors: Richard Gloaguen and Prasad S. Thenkabail

Received: 20 August 2014; in revised form: 30 October 2014 / Accepted: 04 November 2014 / Published: 7 November 2014

\begin{abstract}
Vegetation cover can affect the lithological mapping capability of space- and airborne instruments because it obscures the spectral signatures of the underlying geological substrate. Despite being widely accepted as a hindrance, few studies have explicitly demonstrated the impact vegetation can have on remote lithological mapping. Accordingly, this study comprehensively elucidates the impact of vegetation on the lithological mapping capability of airborne multispectral data in the Troodos region, Cyprus. Synthetic spectral mixtures were first used to quantify the potential impact vegetation cover might have on spectral recognition and remote mapping of different rock types. The modeled effects of green grass were apparent in the spectra of low albedo lithologies for $30 \%-40 \%$ fractional cover, compared to just $20 \%$ for dry grass cover. Lichen was found to obscure the spectra for $30 \%-50 \%$ cover, depending on the spectral contrast between bare rock and lichen cover. The subsequent impact of vegetation on the remote mapping capability is elucidated by considering the outcomes of three airborne multispectral lithological classifications alongside the spectral mixing analysis and field observations. Vegetation abundance was found to be the primary control on the inability to classify large proportions of pixels in the imagery. Matched Filtering outperformed direct
\end{abstract}


spectral matching algorithms owing to its ability to partially unmix pixel spectra with vegetation abundance above the modeled limits. This study highlights that despite the limited spectral sampling and resolution of the sensor and dense, ubiquitous vegetation cover, useful lithological information can be extracted using an appropriate algorithm. Furthermore, the findings of this case study provide a useful insight to the potential capabilities and challenges faced when utilizing comparable sensors (e.g., Landsat 8, Sentinel-2, WorldView-3) to map similar types of terrain.

Keywords: lithological mapping; vegetation; multispectral; geology; Troodos ophiolite

\section{Introduction}

Reflectance measurements in the visible/near-infrared (VNIR) to shortwave infrared (SWIR) wavelength region $(0.4-2.50 \mu \mathrm{m})$ provide diagnostic information that can be used to identify rocks and their constituent minerals [1]. This information is primarily manifest as absorption features that appear at specific wavelengths in the reflectance spectra, corresponding to electronic or vibrational processes in constituent ions and molecular bonds, respectively [2,3]. The processes responsible for these wavelength-specific absorption features have been well-documented based on laboratory spectral analysis of numerous rocks and minerals [1,4-9].

Continuous access to a variety of spaceborne and airborne sensors operating in the VNIR-SWIR wavelength region has seen remote sensing utilized extensively as a tool for lithological mapping [2,10-18]. The standard approach to performing rapid remote mapping involves directly matching image pixel spectra to the reflectance spectra of outcropping lithologies using automated image classification algorithms. Spectral signatures for the lithologies can either be obtained through spectroscopic measurements [16] or extracted from the spectral imagery [13].

The Advanced Spaceborne Thermal Emission and Reflection Radiometer (ASTER) and airborne hyperspectral scanners have arguably been the most commonly utilized instruments for mapping lithologies during the last decade. However, useable up-to-date ASTER imagery has been unavailable since the SWIR detector failure in 2008, whereas hyperspectral imagery is very limited in terms of global coverage because of the need to specially commission airborne surveys. Nevertheless, with the recent launches of Landsat 8 and WorldView-3, and upcoming launch of ESA's first Sentinel-2 satellite in 2015, access to more contemporary imagery should increase considerably. With this in mind, existing datasets acquired using instruments with similar spectral configurations present timely opportunities for gaining useful insights into the anticipated capabilities and limitations of these new satellites for lithological mapping applications (e.g., [19]).

Besides rocks with an inherent lack of spectral distinction, the presence of vegetation cover is arguably the most significant issue affecting the mapping capability of space- and airborne instruments, since vegetation cover can obscure or completely mask the spectral signatures of the underlying geological substrate [20,21]. As a consequence, most lithological mapping studies have focused on arid areas that are essentially barren of vegetation [3]. A few studies have, however, attempted to quantify the effect of fractional vegetation cover on the VNIR-SWIR reflectance spectra 
of various lithologies using spectral mixing analysis. To summarize, just $10 \%$ green grass cover can cause its own spectral features to be imparted on the VNIR-SWIR reflectance spectra of underlying lithologies with low albedo [22]. Dry or dead grass cover can mask spectral features in the SWIR region for as little as 20\%-30\% fractional cover [23], while the VNIR-SWIR reflectance spectra of low albedo lithologies can be obscured by $20 \%-30 \%$ lichen cover [24]. A number of techniques have been developed to try to overcome the effects of vegetation on spectral discrimination of the underlying lithological substrate. These include techniques based on Principal Component Analysis [20], statistical "forced invariance" [25], spectral unmixing [26-31], use of ancillary data [32-34] and correction of diagnostic absorption depths using linear regression models [35,36]. Despite the significant body of research on overcoming the problems posed by vegetation cover, little attention has been paid to demonstrating how the effects observed through spectral mixing analysis translate to remotely sensed imagery. Although few studies have alluded to the impact vegetation can have on remote lithological mapping [22,24,37,38], fewer still have explicitly demonstrated this (e.g., [39]). More comprehensive case studies on the impact of vegetation would help to establish the limitations of various sensors for remote lithological mapping, and may therefore help to ultimately inform which sensor and mapping technique is most suitable for specific regions.

The primary aim of this study is to explicitly determine the impact of vegetation on the lithological mapping capability of airborne multispectral imagery, for a well-documented case study area comprising upper ophiolitic rocks and sedimentary cover. To achieve this, representative spectral signatures for the lithological units are first established using a spectroradiometer. To help anticipate and quantify the potential impact that vegetation cover might have on mapping using the remotely sensed data, synthetic spectra are generated by linearly mixing the representative spectra of the lithologies with the spectra of several common vegetation types. The relevance of the modeled obscuring and masking effects of vegetation with respect to those in the remotely sensed imagery is then determined. Lastly, the impact of vegetation on the remote mapping capability is subsequently elucidated by considering the outcome of conventional airborne multispectral lithological classification approaches alongside the spectral mixing analysis and field observations.

\section{Study Area}

The study area is located in the northern foothills of the Troodos mountains, on the eastern Mediterranean island of Cyprus (Figure 1). Basement rocks consist of an uplifted slice of oceanic crust and lithospheric mantle - the Troodos ophiolite, which was created through sea-floor spreading [40,41]. The ophiolite forms a dome-like structure centered on Mt. Olympus (1952 m), and stratigraphically comprises a mantle sequence of harzburgites, dunites and a serpentinite diapir, a largely gabbroic plutonic complex, a sheeted dyke complex, a lava sequence and oceanic sediments [42]. The complex is exposed along the northern slopes of the range, with the shallowest stratigraphic levels exposed at decreasing elevation towards the north. The study area encompasses the contact between the lava sequence and overlying sedimentary cover sequences. The four main lithological units that outcrop within the $16 \mathrm{~km}^{2}$ study area are the Basal Group (generally comprising 80\%-90\% dykes and 10\%-20\% lavas), pillow lavas (divided into Upper and Lower sub-units), late Cretaceous to early Miocene chalky marls of the Lefkara Formation, and alluvium-colluvium derived from a variety of parent rock types. 
The main primary and secondary constituent minerals for each lithological unit (see table in Figure 1) were identified based on petrological descriptions by Gass [43]. Due to the chemistry and formation of the rocks, there are some inherent similarities in the mineralogical compositions of the lithological units, especially within the volcanic sequence and between alluvial-colluvial sediments and their parent rocks. Of the two published geological maps of the region, the most recent, but coarser 1:250,000-scale shown in Figure 1 is considered to be the most geologically accurate [44].

Figure 1. Location and geology of the Troodos ophiolite, Cyprus. Primary and secondary constituent minerals are based on the petrological descriptions by Gass (1960). Digital geology was provided by the Geological Survey Department of Cyprus.

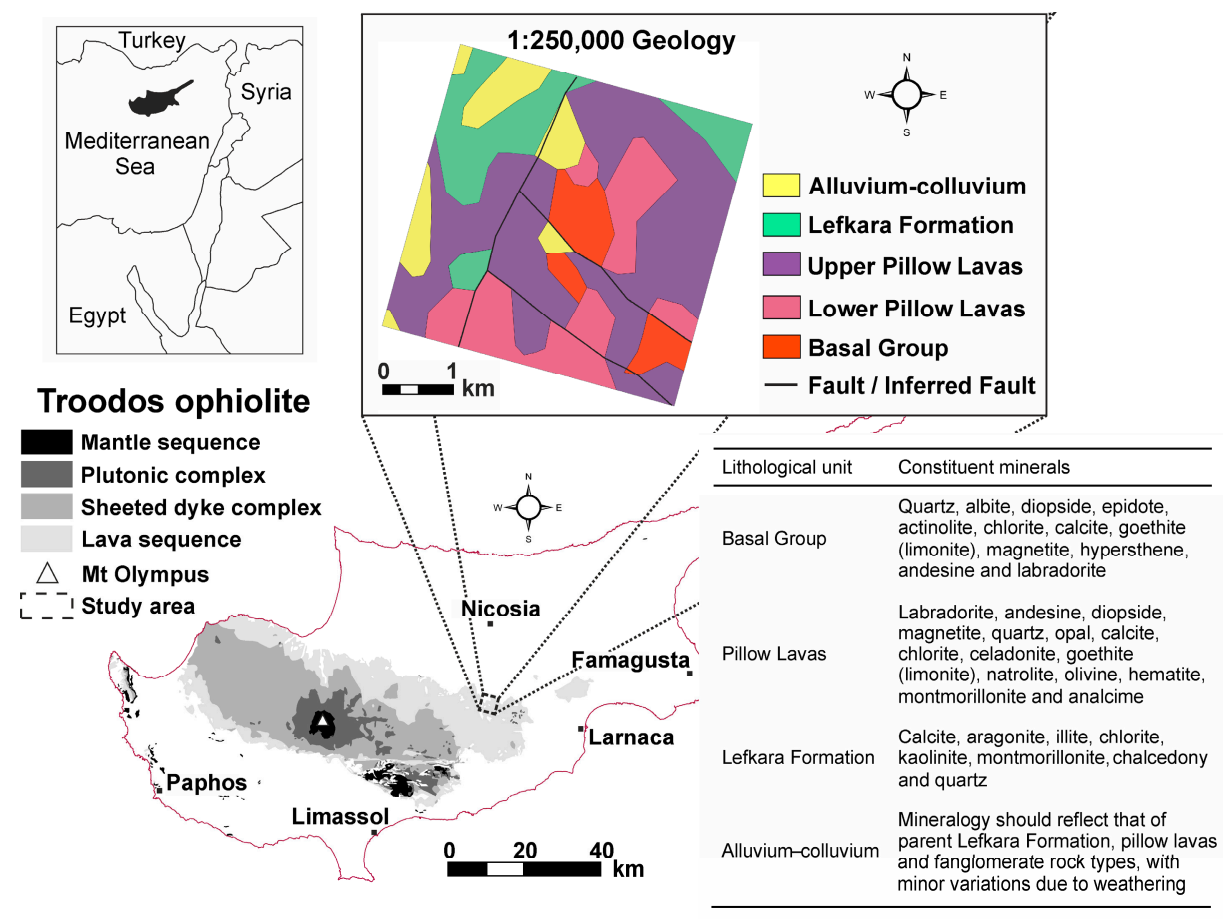

Vegetation cover in the study area is ubiquitous, typically covering $30 \%-90 \%$ of the surface at length scales greater than $1 \mathrm{~m}$ (Figure 2). In terms of decreasing abundance, the predominant vegetation types are dry grass, lichen cover on outcrops, green grass, crops (e.g., cereals, olive groves) and scrub [45]. Less common vegetation cover consists of isolated pine and oak trees, through to dense thickets and copses.

Anthropogenic influences on the landscape include the disused Mathiati mine and spoil heaps in the southwest, Agia Varvara Lefkosias village in the north, and agricultural activity largely confined to the northwest. Despite the complexity of the terrain, the geology of this area is well-understood and documented, therefore making it an excellent case study area for highlighting the impact of vegetation cover on the remote lithological mapping capabilities. 
Figure 2. Field photographs showing the range of vegetation types and abundances typically found growing on the four main lithologies in the study area. Predominant vegetation associations are: alluvium-colluvium — crops and grasses; Basal Group and Lefkara Formation—-grasses and scrub; pillow lavas_-lichen and scrub.

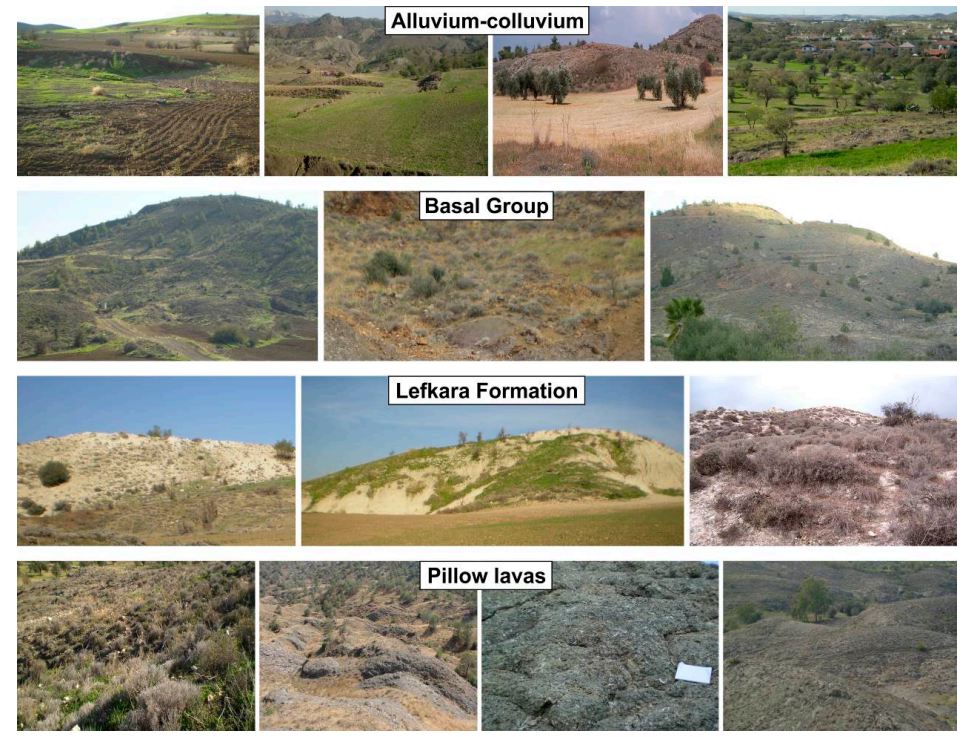

\section{Methods}

The methodology employed in this study to elucidate the impact of vegetation cover on mapping of lithologies using remotely sensed spectral imagery comprised three main aspects. These were: (1) establishing spectral signatures for the lithological units, (2) quantifying the effects of vegetation cover through spectral mixing analysis, and (3) investigating the impact on classifications performed using airborne multispectral imagery.

\subsection{Spectral Signatures of the Lithological Units}

Reflectance spectra of rock and soil samples from the study area were established for input to the spectral mixing analysis and subsequent mapping using remotely sensed spectral imagery. Spectral measurements of approximately 40 samples were made using an Analytical Spectral Devices (ASD) FieldSpec $^{\circledR}$ Pro spectroradiometer that records reflected energy in the $0.35-2.50 \mu \mathrm{m}$ wavelength region. To account for local mineralogical variation within lithologies, multiple samples from across the study area were collected and analyzed for each unit. Numerous spectra were acquired for each sample to account for intra-sample spectral variation caused by heterogeneity in both the surface mineralogy and micro-topography. To illustrate the effects of vegetation on spectral recognition of the lithologies, care was taken to ensure that only completely vegetation-free samples were analyzed. Consequently, the observed spectral characteristics only reflect the elemental and mineralogical composition of the lithologies. The resulting $\sim 300$ reflectance spectra were converted to absolute reflectance using a calibrated Spectralon ${ }^{\circledR}$ panel, and then processed to establish average fresh and weathered surface spectra (where appropriate) for each lithological unit. 


\subsection{Modeling the Impact of Vegetation on the Spectra of the Four Lithologies}

Due to the presence of ubiquitous, abundant vegetation cover at length scales of $1 \mathrm{~m}$ or greater, the majority of pixels in the remotely sensed imagery - and thus their spectra-will encompass mixtures of bare rock/soil and vegetation. To help quantify the effects of sub-pixel (fractional) vegetation cover on the spectra of the lithologies, and subsequently anticipate its impact on mapping using the remotely sensed data, synthetic reflectance spectra were generated by mixing the representative spectra of the lithologies with the spectra of common vegetation types [22-24,35]. Spectral mixing (or unmixing) is based on the principle that the resulting spectrum for an image pixel containing a mixture of several distinct materials will be a combination of all of their individual reflectance spectra [46]. Spectral mixing models usually consider composite image pixel spectra to be a linear combination of the spectra of each material, weighted according to their fractional abundances [47]. For an image pixel containing two different surface materials, lithological unit $U$ and vegetation type $V$, this model can be written as:

$$
R_{\text {obs }}(\lambda)=X_{U} R_{U}(\lambda)+X_{V} R_{V}(\lambda)
$$

and

$$
X_{U}+X_{V}=1
$$

where $R_{o b s}(\lambda)$ is the observed image pixel spectrum, $X_{U}$ is the relative proportion of lithology $U$ within the pixel, $R_{U}(\lambda)$ is the sensor-convolved reflectance spectrum of lithology $U, X_{V}$ is the relative proportion of vegetation type $V$ within the pixel, and $R_{V}(\lambda)$ is the sensor-convolved reflectance spectrum of vegetation type $V$.

Synthetic spectra were generated using this two end-member model to mix the sensor-convolved spectrum of each lithological unit with increasing proportions of the spectrum of the vegetation types commonly found growing on each unit. The vegetation types comprised lichen, green grass and dry grass, which are the most abundant in the study area.

\subsection{Remote Lithological Mapping and the Impact of Vegetation}

The capability of airborne multispectral imagery for lithological mapping of the study area was assessed using a standard direct approach of matching the image pixel spectra to the spectral signatures of the lithologies. In summary, this approach comprised data calibration, image classification, and an assessment of the classification performance. The impact of vegetation on the lithological mapping capability was subsequently investigated by considering the classification results alongside information on vegetation abundance. A more detailed description of each methodological step is provided below.

\subsubsection{Airborne Multispectral Imagery}

Airborne multispectral imagery for the study area was acquired using a Daedalus 1268 Airborne Thematic Mapper (ATM) instrument in May 2005. The ATM instrument is a passive multispectral scanner that measures electromagnetic radiation in eleven spectral wavebands located in the visible to thermal infrared wavelength range, with a spectral configuration similar to that of the Landsat 8 , Sentinel-2 and WorldView-3 satellites (Table 1). Five overlapping flight-lines of imagery were 
acquired, evaluated and processed to correct for issues such as atmospheric haze and across-track brightness differences, resulting in a single image mosaic providing full coverage of the study area at a spatial resolution of $4 \mathrm{~m}$ [34]. Wavebands 1 and 11 were discarded from further analysis since these lie outside of the VNIR-SWIR wavelength range of interest.

Table 1. Spectral configuration of the Airborne Thematic Mapper (ATM) sensor in comparison with Landsat 8, Sentinel-2 and WorldView-3 satellites.

\begin{tabular}{cccccc}
\hline $\begin{array}{c}\text { ATM } \\
\text { Band }\end{array}$ & $\begin{array}{c}\text { Wavelength } \\
(\boldsymbol{\mu m})\end{array}$ & Spectral Region & $\begin{array}{c}\text { Equivalent } \\
\text { Landsat 8 Band }\end{array}$ & $\begin{array}{c}\text { Equivalent } \\
\text { Sentinel-2 Band }\end{array}$ & $\begin{array}{c}\text { Equivalent } \\
\text { WorldView-3 } \\
\text { Band }\end{array}$ \\
\hline 1 & $0.42-0.45$ & Ultraviolet/blue & 1 & 1 & Coastal \\
2 & $0.45-0.52$ & Blue & 2 & 2 & Blue \\
3 & $0.52-0.60$ & Green & 3 & 3 & Green \\
4 & $0.60-0.62$ & Yellow/orange & & & Yellow \\
5 & $0.63-0.69$ & Red & 4 & 5 & Red \\
6 & $0.69-0.75$ & Near-infrared & & $7,8,8 \mathrm{a}$ & Red Edge \\
7 & $0.76-0.90$ & Near-infrared & 5 & 9 & Near-IR1 \\
8 & $0.91-1.05$ & Near-infrared & & 11 & SWIR-2,3,4 \\
9 & $1.55-1.75$ & Shortwave infrared & 6 & 12 & SWIR-5,6,7,8 \\
10 & $2.08-2.35$ & Shortwave infrared & 7 & & \\
11 & $8.50-13.00$ & Thermal infrared & 10 and 11 & & \\
\hline
\end{tabular}

\subsubsection{Data Calibration}

In order to match the ATM image pixel spectra to the spectroscopy-derived spectral signatures of the lithologies, it is essential to ensure that the datasets are compatible. To achieve this, the spectral signatures of the lithologies were first convolved to the ATM wavebands (bands 2-10) by using the Spectral Library Resampling tool in ENVI 4.8 in conjunction with a filter function file containing the sensor response (bandpass) for each ATM waveband. Next, the ATM imagery was converted from at-sensor radiance to absolute reflectance. With atmosphere correction via rigorous radiative transfer models ruled out due to a lack of atmospheric measurements at the time of the airborne survey, the correction was instead achieved using the Empirical Line method [48]. The Empirical Line method performs data calibration by exploiting the linear relationship between pixel values (digital numbers; DNs) in the imagery and the reflectance of surface materials found within the scene [49]. Calibration requires at least two ground surfaces with contrasting albedos [50,51], with accurate calibration results attainable using between 2 and 4 different surfaces [52,53]. Successful Empirical Line calibration of the ATM imagery to absolute reflectance was performed here in ENVI 4.8 using three homogenous surfaces of low, moderate and high albedo. 


\subsubsection{Image Classification}

Lithological maps were generated using a conventional approach of classifying the calibrated ATM multispectral imagery in conjunction with the ATM-convolved spectral signatures of the lithologies. Classification was performed using three different algorithms that are typically used for lithological mapping applications: Spectral Angle Mapper, Matched Filtering and Spectral Feature Fitting.

The Spectral Angle Mapper (SAM) algorithm calculates the spectral similarity between an image pixel spectrum and a reference spectrum as the angle between their vectors in a space with dimensionality equal to the number of bands [46]. It is widely considered to be relatively insensitive to gain factors (e.g., variations in topography and illumination) because these only alter the lengths of the vectors and not the angle between them [10]. The SAM algorithm was applied to the ATM imagery by using the ATM-convolved spectral signatures as the reference spectra. Spectral angle values in the output "rule image" for each reference spectrum range between 0 and $\pi / 2$ radians, signifying a perfect match and no match, respectively. Pixels closely matching each reference spectrum were extracted by applying a $0-0.16$ radian threshold (i.e., within $10 \%$ of a perfect match) to each rule image.

The Matched Filtering (MF) algorithm is an orthogonal sub-space projection operator [54], capable of identifying sub-pixel abundances of reference spectra through partial unmixing of image pixel spectra [14]. Utilizing the Minimum Noise Fraction (MNF) Transformation [55], the MF algorithm first maximizes the spectral response of the target material in each image pixel whilst simultaneously suppressing that of the interfering background materials, before then comparing the enhanced spectrum of each pixel to that of the reference spectrum [12]. The MF output is a grey-scale MF score image for each reference spectra, with pixel values (MF scores) of 0 or less corresponding to the background materials $(0 \%$ abundance) and scores near to 1 representing a close match (100\% abundance) to the reference spectrum [56,57]. A threshold was applied to each MF-score image in order to extract pixels that represent $\mathrm{a} \geq 90 \%$ match to each of the reference spectra.

Spectral Feature Fitting (SFF) performs classification by comparing continuum-removed pixel spectra to the continuum-removed reference spectra using a two-stage approach, comprising image scaling and least-squares fitting [58-60]. By utilizing the continuum-removed spectra, the SFF algorithm is less sensitive to variations in illumination, grain size and impurities [61-63]. Pixels closely matching each reference spectrum were extracted by applying a threshold to a "fit" image, which was computed as the ratio of the "scale" and root-mean-square (RMS) error images output by the SFF algorithm. In each case, the appropriate threshold was defined based on the overall spatial coherence between classified pixels and the known geology. Due to a lack of spectral coverage of the ATM sensor in the SWIR wavelength region, the SFF algorithm was applied across the entire VNIR-SWIR range covered by ATM bands 2-10. This helps retain the broader "shape-of-the-curve" spectral features that are often lost through continuum removal targeted at absorptions within narrower wavelength ranges [18]. Considering the spectral sampling and resolution of the ATM sensor, it is likely to be these broader features that prove more diagnostic of the lithologies. 


\subsubsection{Classification Performance}

Lithological classification performances of the three algorithms were evaluated through both a qualitative visual assessment and a quantitative accuracy assessment. The qualitative assessment involved comparing the classification results with observations made in the field. The accuracy was assessed quantitatively by deriving confusion matrices, which detail the comparison of the known lithological class identities of a set of validation pixels to the classes assigned through classification [64]. Validation pixels were selected from several regions of interest (ROIs) that were defined to represent each lithological unit. The ROIs were defined across the study area based purely on the known geology-i.e., completely independent of the type or abundance of vegetation cover - by using extensive field observations in conjunction with high-resolution QuickBird satellite imagery. Validation pixels were then sampled from the ROIs using a random stratified sampling protocol to ensure proportional representation and avoiding spatial autocorrelation within the validation dataset $[65,66]$, and to ensure that the chosen pixels represent a range of vegetation abundances for subsequent analysis. A total subset of 12,946 validation pixels ( $\geq 2451$ pixels for each lithology) was determined to be a statistically valid sample size for estimating the accuracy of the entire mapped scene [34].

\subsubsection{Vegetation Abundance}

A vegetation index was derived from the calibrated ATM imagery to help investigate the impact of vegetation abundance on spectral recognition and remote mapping of the lithologies. The Soil-Adjusted Vegetation Index (SAVI) of Huete [67] was selected for this purpose because it is directly proportional to fractional vegetation cover and minimizes soil background influences [68], thus making it more suitable for use in arid or semi-arid environments than other common indices [69]. The SAVI is derived using:

$$
\mathrm{SAVI}=(1+L) \frac{B_{7}-B_{5}}{B_{7}+B_{5}+L}
$$

where $B_{5}$ and $B_{7}$ is the reflectance in the calibrated ATM bands 5 and 7, respectively, and $L=1.0,0.5$ or 0.25 for increasing vegetation densities. An intermediate value of $L=0.5$ was selected to represent the typical vegetation density observed in the study area. Resulting SAVI values were scaled between 0 and 1 , corresponding to $0-100 \%$ fractional vegetation cover within any given pixel.

\section{Results and Discussion}

\subsection{Spectral Signatures of the Lithological Units}

Representative VNIR-SWIR reflectance spectra established for the fresh and weathered surfaces of the four main lithologies are shown in Figure 3. Rocks of the Basal Group exhibit low albedo, with fresher surfaces (Figure 3a) exhibiting a higher albedo than weathered surfaces (Figure 3b). Dark to opaque and spectrally featureless minerals such as hypersthene, diopside, labradorite and magnetite account for the low albedo of Basal Group rocks. The notable, observed difference in albedo between fresh and weathered surfaces is likely due to a weathering-induced decrease in the grain size, which subsequently decreases the reflectance across the VNIR-SWIR wavelength region [70]. The broad Fe-O 
charge-transfer absorption feature at wavelengths less than $0.55 \mu \mathrm{m}$ is associated with goethite [2], which occurs in Basal Group rocks following the oxidation of fine-grained sulphides such as pyrite [71]. The prominent absorption band centered on $2.30 \mu \mathrm{m}$, and multiple weak absorption features at $2.25 \mu \mathrm{m}$, $2.35 \mu \mathrm{m}$ and $2.40 \mu \mathrm{m}$, are likely due to a combination of $\mathrm{OH}$ stretching with the $\mathrm{Mg}-\mathrm{OH}$ bending mode $[1,12]$ — possibly attributed to the occurrence of chlorite [72].

Figure 3. Spectral signatures of the four main lithologies. Reflectance spectra for (a) fresh rock surfaces, (b) weathered rock surfaces and (c) alluvium-colluvium.
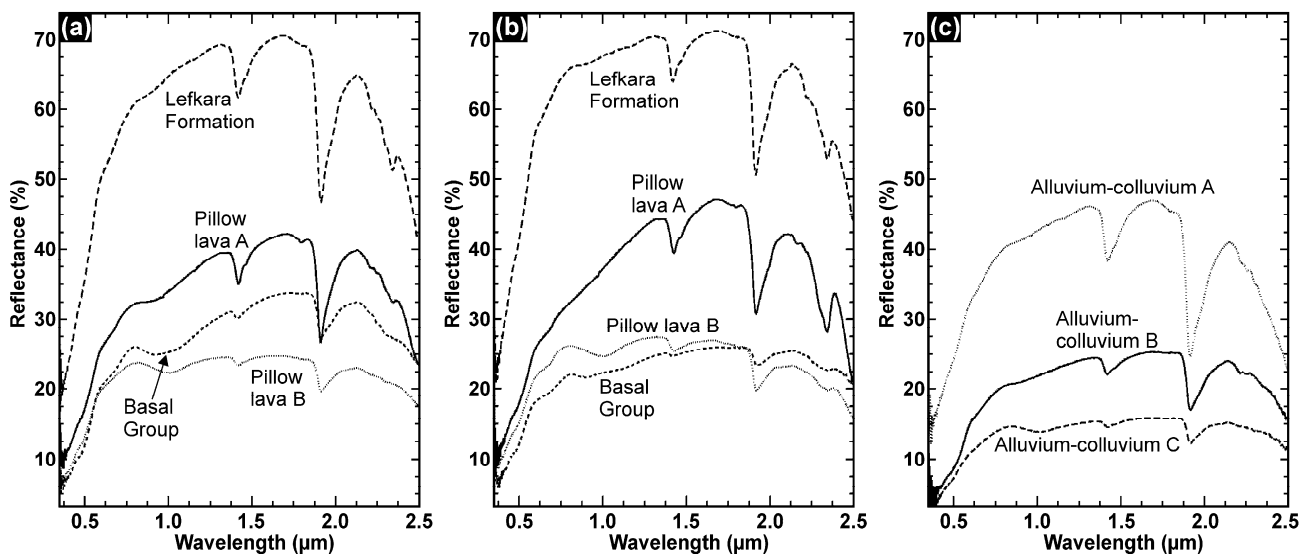

Figure 4. Spectral signatures of the four main lithologies convolved to the ATM bandpasses (wavebands indicated by red text). (a) Basal Group, (b) pillow lavas, (c) Lefkara Formation and (d) alluvium-colluvium. Spectra vertically offset for clarity.
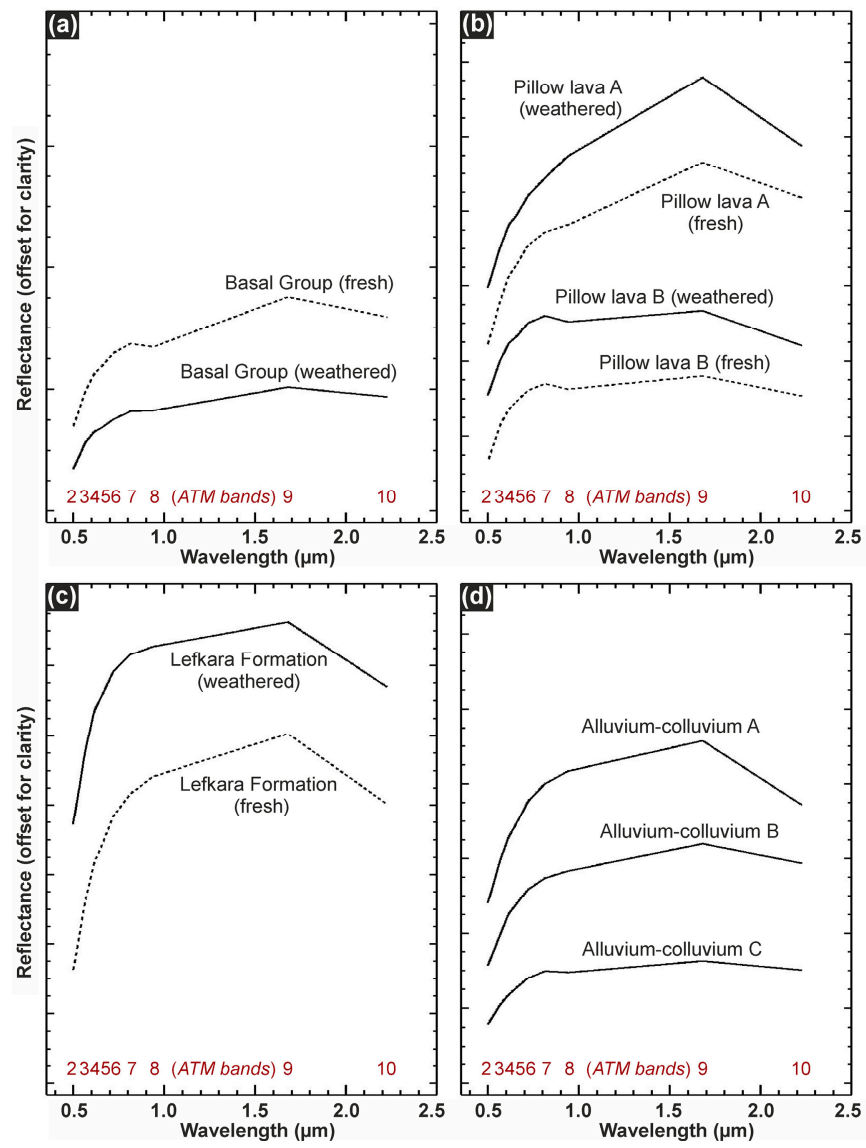
Two types of pillow lavas_-"Pillow lava A" (PLA) and "Pillow lava B" (PLB)—were identified during spectral analysis of the samples (Figure 3a,b). Through comparison with the spectra acquired by van der Meer et al. [10] using a Portable Infrared Mineral Analyzer, the weathered PLA spectrum is consistent with that of the "Upper Pillow Lavas", while the weathered PLB spectrum resembles that of the "Lower Pillow Lavas". Fresh and weathered PLA surfaces exhibit a broad charge-transfer absorption feature at wavelengths less than $0.55 \mu \mathrm{m}$. This is most likely associated with Fe-O in hematite [73], which also contributes to the pink color of the extensive calcite veining in the "Upper Pillow Lavas" [43]. The weak absorption near $2.16 \mu \mathrm{m}$ exhibited by weathered surfaces and a common stronger broad feature near $2.34 \mu \mathrm{m}$ are due to respective combinations and overtones associated with the $\mathrm{CO}_{3}{ }^{2-}$ ion in calcite [1]. The general appearance of the PLB spectra closely resembles that of the Basal Group. This is unsurprising because the PLB are consistent with the "Lower Pillow Lavas", and the distinction between the "Lower Pillow Lavas" and Basal Group is primarily based on dyke abundances rather than mineralogy [74]. As with Basal Group rocks, goethite (limonite) is responsible for the broad Fe-O charge-transfer band at wavelengths less than $0.55 \mu \mathrm{m}$ in the spectra of both fresh and weathered surfaces [1]. Molecular water absorption features observed at $1.42 \mu \mathrm{m}$ and $1.91 \mu \mathrm{m}$ have a much smaller band depth than those exhibited by PLA rocks. Since weathering enhances these water absorption features [10], the greater band depths exhibited by PLA rocks are probably the result of more prolonged weathering due to their higher stratigraphic position. A $2.26 \mu \mathrm{m}, 2.30 \mu \mathrm{m}$ and $2.34 \mu \mathrm{m}$ absorption triplet in the weathered PLB spectrum is attributed to combinations of $\mathrm{Al}, \mathrm{Fe}, \mathrm{Mg}-\mathrm{OH}$ absorptions, characteristic of celadonite [75].

Lefkara Formation rocks exhibit a high albedo (Figure 3a,b) due to the predominance of carbonate minerals such as calcite and aragonite. The occurrence of these minerals is indicated by the broad absorption featured centered on $2.34 \mu \mathrm{m}$ and the associated feature near $2.50 \mu \mathrm{m}$, which represent combination and overtone bands of the $\mathrm{CO}_{3}$ fundamentals [9]. The weak absorption superimposed on the broad feature at $2.21 \mu \mathrm{m}$ is associated with the Al-OH bond in clay minerals such as kaolinite, illite and montmorillonite [9,75].

The alluvium-colluvium spectra identified from the samples (Figure 3c) were found to comprise regolith material derived from the Lefkara Formation ("Alluvium-colluvium A"), fanglomerate ("Alluvium-colluvium B") and pillow lavas ("Alluvium-colluvium C"). As anticipated, the overall appearance of the spectra for "Alluvium-colluvium A" and "Alluvium-colluvium C" are similar to those of their parent rocks. However, the notable absence of the broad 2.19-2.38 $\mu \mathrm{m}$ absorption centered on $2.34 \mu \mathrm{m}$ and associated feature at $2.50 \mu \mathrm{m}$ in "Alluvium-colluvium A" suggests that weathering processes have removed the $\mathrm{CO}_{3}$ minerals from the parent Lefkara Formation rocks during regolith formation. Likewise, weathering of the pillow lavas (particularly PLA) probably accounts for the absence of combinations and overtones of $\mathrm{CO}_{3}$ fundamentals in calcite in the "Alluvium-colluvium C" spectrum. Regolith of the "Alluvium-colluvium B" originates from continental fanglomerates, which are generally derived from heterogeneous mixtures of the igneous rocks [43]. The spectrum exhibits several familiar absorption features linked to the presence of iron and clays. The absorption feature near $0.48 \mu \mathrm{m}$ superimposed onto a broad charge-transfer band at wavelength less than $0.58 \mu \mathrm{m}$, and the absorption at $0.91 \mu \mathrm{m}$ are typical ferric iron features of goethite (limonite). A prominent absorption near $2.21 \mu \mathrm{m}$ and an addition associated weak feature near $2.25 \mu \mathrm{m}$ resemble Al-OH absorptions in illite [58]. 
Convolving the spectral signatures of the lithologies to the ATM bandpasses leads to a considerable loss of information on many diagnostic absorption features, particularly in the SWIR region (Figure 4). Nonetheless, the albedo and general shape of the spectra are retained, which should still enable discrimination between contrasting lithologies, such as the Lefkara Formation and Basal Group. Discrimination of the alluvium-colluvium and the parent rocks, and Basal Group and Pillow lavas, however, is likely to be more difficult due to their spectral similarity in the ATM-convolved spectra.

\subsection{Impact of Vegetation on Spectral Recognition of the Lithologies}

The effects of vegetation on the ATM-convolved spectra of the lithologies were investigated by linearly mixing their spectra with the appropriate vegetation spectra for increasing amounts of fractional cover. The resulting synthetic spectra are shown in Figures 5-7.

Figure 5. Modeled effect of increasing green grass abundance on the ATM-convolved spectra of the (a) Basal Group, (b) "Pillow lava A" (PLA), (c) "Pillow lava B" (PLB), (d) Lefkara Formation and Alluvium-colluvium (e) "A", (f) "B" and (g) "C". Spectra vertically offset for clarity.
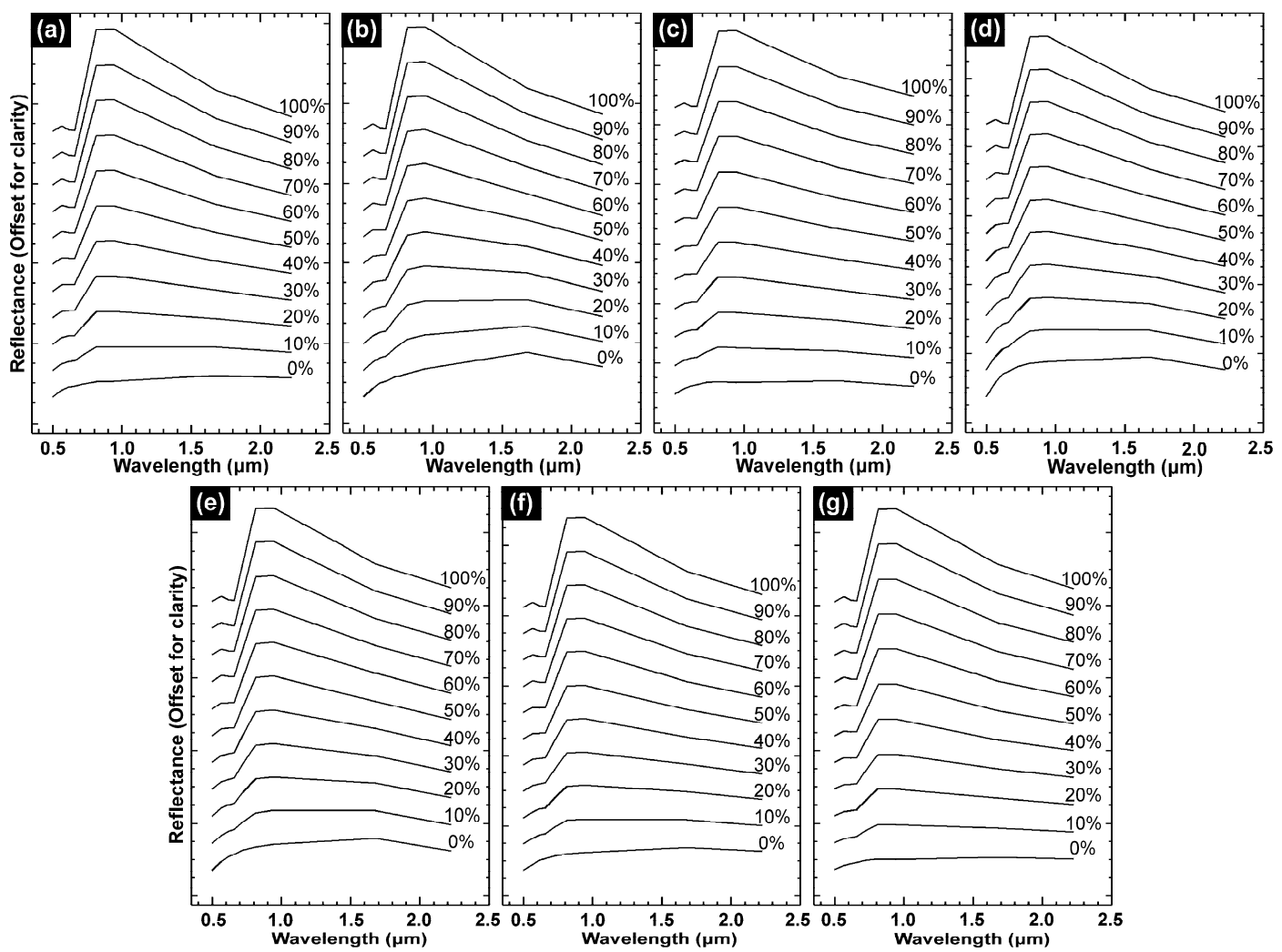

The effects of green grass on the spectra are pronounced for all lithologies (Figure 5), with the most notable being the impartation of a characteristic chlorophyll absorption feature at $0.65-0.70 \mu \mathrm{m}$, and moderate and high reflectance peaks at $0.55 \mu \mathrm{m}$ and $0.80-0.90 \mu \mathrm{m}$, respectively. The combined effect of the $0.65-0.70 \mu \mathrm{m}$ absorption feature and $0.55 \mu \mathrm{m}$ reflectance peak on spectral recognition of the lithologies can be quantified by considering how increasing vegetation fractional cover alters the reflectance ratio for ATM waveband $3\left(B_{3}\right)$ and $5\left(B_{5}\right)$. The $B_{3} / B_{5}$ ratio reveals curvilinear responses to 
increasing vegetation abundance for all lithologies, increasing with upward concavity from $\sim 0.8$ for $0 \%$ fractional green grass cover to 1.6 for $100 \%$ (Figure $8 \mathrm{a}$ ). A ratio $\leq 1.0$ for all lithologies is observed for abundances of $0-30 \%$, indicating that the lithologies are generally not unduly affected by the $0.55 \mu \mathrm{m}$ and $0.65-0.70 \mu \mathrm{m}$ features when green grass represents a small proportion of the spectral mixture. Between $30 \%$ and $40 \%$ cover, however, the $B_{3} / B_{5}$ ratio for the low albedo lithologies (i.e., Basal Group and "Alluvium-colluvium C") attains to 1.0 due to the presence of these spectral features. This corresponds to significant obscuring, and subsequent masking of the spectra of these lithologies with yet further increases in green grass cover. The spectra of the moderate albedo lithologies (i.e., PLA, PLB, "Alluvium-colluvium A", "Alluvium-colluvium B") become masked by the $0.55 \mu \mathrm{m}$ and $0.65-0.70 \mu \mathrm{m}$ spectral features of green grass at fractional cover of 50\%-65\%. The Lefkara Formation spectrum is less sensitive to green grass because of its high albedo; only becoming completely masked when fractional cover reaches $75 \%$. These findings are consistent with those of Siegal and Goetz [22] and Murphy and Wadge [23], which report that the spectra of lower albedo rocks and soils (i.e., andesite) are masked by $30 \%$ green grass cover, whereas rocks and soils with moderate (i.e., limestone) and higher albedos (i.e., granite) are masked by $50 \%-60 \%$ and $70 \%-80 \%$ cover, respectively.

Figure 6. Modeled effect of increasing dry grass abundance on the ATM-convolved spectra of the (a) Basal Group, (b) "Pillow lava A" (PLA), (c) "Pillow lava B" (PLB), (d) Lefkara Formation and Alluvium-colluvium (e) "A", (f) "B" and (g) "C". Spectra vertically offset for clarity.

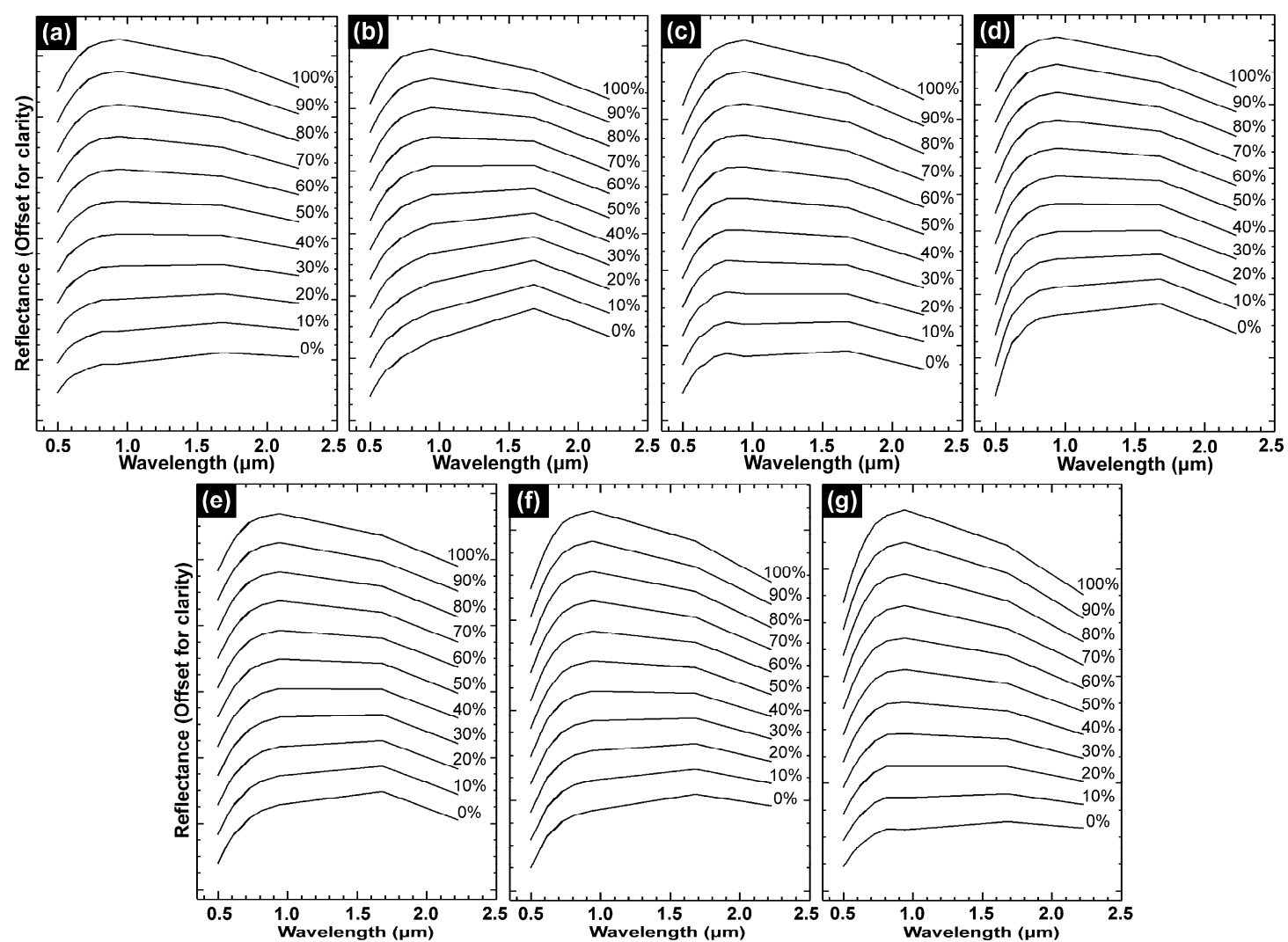


Figure 7. Modeled effect of increasing lichen abundance on the ATM-convolved spectra of the (a) "Pillow lava A" (PLA), (b) "Pillow lava B" (PLB) and (c) Lefkara Formation. Spectra vertically offset for clarity.
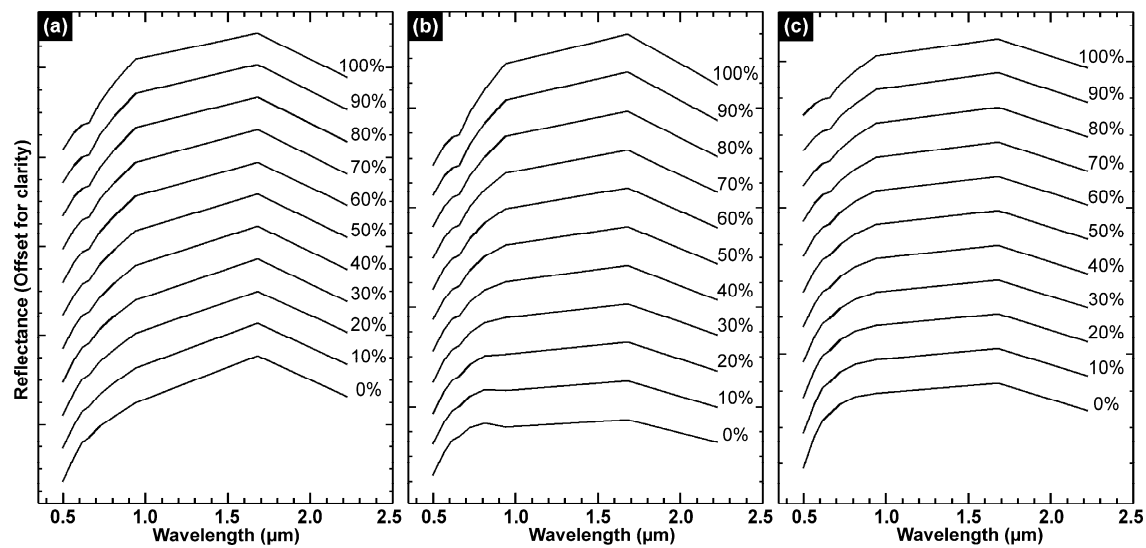

The predominant effect of dry grass cover is to produce a change of the direction of the slope in the reflectance spectra of all lithologies at $0.95-1.70 \mu \mathrm{m}$ (Figure 6). The response of this characteristic change of slope to increasing fractional dry grass cover can be quantified by analyzing the ATM $B 8 / B 9$ ratio. Lithological variations are observed in the response of the $B 8 / B 9$ ratio for increasing fractional dry grass abundance (Figure 8b). Moderate-to-high albedo lithologies (i.e., "Alluvium-colluvium A", Lefkara Formation, PLA) exhibit concave-up curvilinear responses in $B_{8} / B_{9}$ for increasing fractional cover, whereas the remaining low-to-moderate albedo units exhibit linear or slightly concave-down responses. Spectral recognition of the underlying lithologies is possible for fractional dry grass cover $<20 \%$ while $B_{8} / B_{9}$ has a value $<1.0$. At approximately $20 \%$ dry grass cover, the spectra of the lower albedo "Alluvium-colluvium C" and PLB units are significantly obscured when the slope in the reflectance spectra at $0.95-1.70 \mu \mathrm{m}$ has a zero gradient. With the exception of the PLA unit, all remaining spectra become obscured at 35\%-40\% cover. The inherently low $B_{8} B$ B ratio for PLA results in this unit being less affected by the dry grass spectra until fractional cover reaches $65 \%$. Again, these observations concur with those of Murphy and Wadge [23], which indicated that the SWIR spectral features can be masked by as little as $20 \%-30 \%$ dry or dead vegetation for lower albedo soils, and $50 \%-60 \%$ for granitic soils with a higher albedo. The observations of both the current study and that of Murphy and Wadge [23] suggest that the obscuring effect of dry grass is generally more significant than that of green grass. In contrast, Siegal and Goetz [22] concluded that green vegetation has a greater obscuring effect than dry or dead vegetation across the full VNIR-SWIR wavelength range, with low-to-moderate albedo rocks still recognizable despite $60 \%$ dry sage cover. Indeed, across this wider wavelength range, the more visually pronounced spectral features in the VNIR region-particularly the reflectance peak at $0.80-0.90 \mu \mathrm{m}-$ do suggest that green grass has a greater impact on the spectra of the lithologies than dry grass (see Figures 5 and 6). Nevertheless, the variation in the observed effects between these studies can be mainly attributed to their largely disparate combinations of lithology and vegetation species, in addition to differences in the spectral range and resolution of the spectroscopic measurements. 
Figure 8. Modeled responses of ATM band ratios to increasing abundance of (a) green grass, (b) dry grass and (c) lichen.

(a)

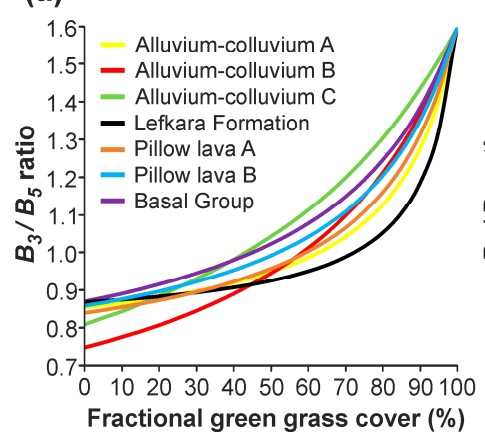

(b)

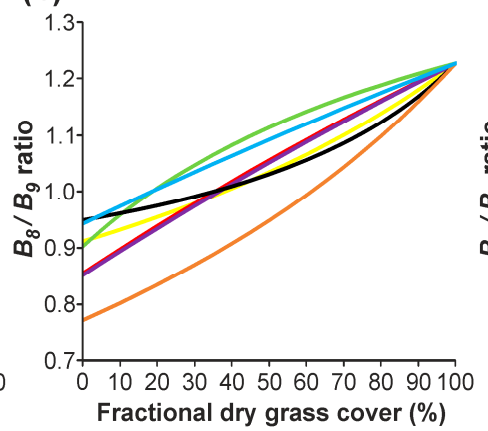

(c)

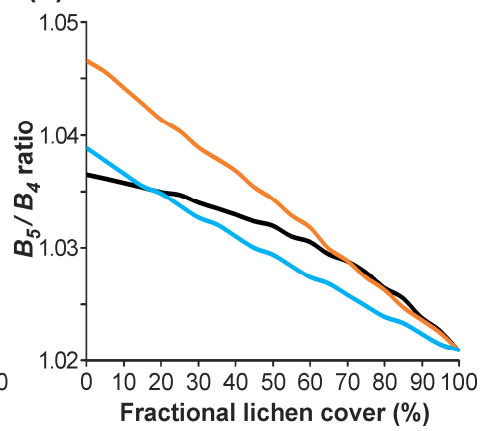

Lichen cover affects spectral recognition of its associated lithologies by imparting a subtle chlorophyll absorption feature near $0.65-0.70 \mu \mathrm{m}$ (Figure 7). The response of this subtle feature to increasing lichen cover can be quantified using the ATM $B_{5} / B_{4}$ ratio (Figure $8 \mathrm{c}$ ). For the pillow lavas (PLA and PLB), the response is linear, decreasing towards a value of 1.02 as the absorption feature at $0.65-0.70 \mu \mathrm{m}$ becomes progressively more pronounced in the composite spectra. On the other hand, the Lefkara Formation exhibits a slight decreasing concave-down trend. In keeping with the findings of Satterwhite et al. [37], the effect of lichen is dependent on the spectral contrast between the lithology and the lichen covering its surface, with a higher spectral contrast associated with a greater effect. Specifically, increased lichen cover acts to increase the reflectance of the low albedo PLB spectrum and decrease that of the high albedo Lefkara Formation (i.e., the units with high spectral contrast), while having a lesser effect on the PLA (with low spectral contrast). The $B_{5} / B_{4}$ responses further corroborate this spectral contrast-effect relationship by revealing that the $0.65-0.70 \mu \mathrm{m}$ absorption affects the spectra of the Lefkara Formation and PLB at much lower fractional lichen cover than for the PLA. This chlorophyll absorption feature is significantly pronounced in the spectra of the PLA and Lefkara Formation for fractional lichen abundance of 30\%, before complete masking occurs at approximately $50 \%$ for PLB and $75 \%$ for the Lefkara Formation. Due to their very similar reflectance in the VNIR-SWIR range, the PLA spectrum is initially more resistant to the effect of the $0.65-0.70 \mu \mathrm{m}$ absorption feature until lichen abundance reaches 50\%. Complete masking of the PLA spectrum occurs when fractional lichen cover exceeds 75\%. Similarly, Ager and Milton [24] reported that the spectra of lithologies (i.e., hornfels and slates) with high spectral contrast between rock and lichen were obscured by $20 \%-30 \%$ lichen cover and masked by $40 \%-50 \%$ cover. Furthermore, granite with little spectral contrast was found to be generally obscured by $50 \%-60 \%$ lichen cover and completely masked at cover exceeding $80 \%$.

\subsection{Implications for Spectral Recognition Using Airborne Multispectral Imagery}

Synthetic spectral mixing analysis enables the theoretical effects of vegetation on the spectra of the lithologies to be studied. The relevance of the modeled effects above with respect to those in the imagery was determined by computing the response of the image-derived ATM $B{ }_{8} / B$ g band ratio to increasing vegetation cover, for each lithology. To achieve this, the $B 8 / B 9$ band ratio and corresponding SAVI values were extracted for a subset of pixels known to correspond to each of the lithologies on 
the ground; the responses were subsequently modeled using regression analysis. The $B 8 / B 9$ band ratio was chosen to be consistent with SAVI values, which should primarily reflect the abundance of dry grassy vegetation contained within each pixel, since this is the dominant type of vegetation cover in the study area.

Figure 9. Image-derived responses of the ATM $B_{8} / B_{9}$ band ratio to increasing Soil-Adjusted Vegetation Index (SAVI), where SAVI reflects the abundance of predominantly dry grassy vegetation.

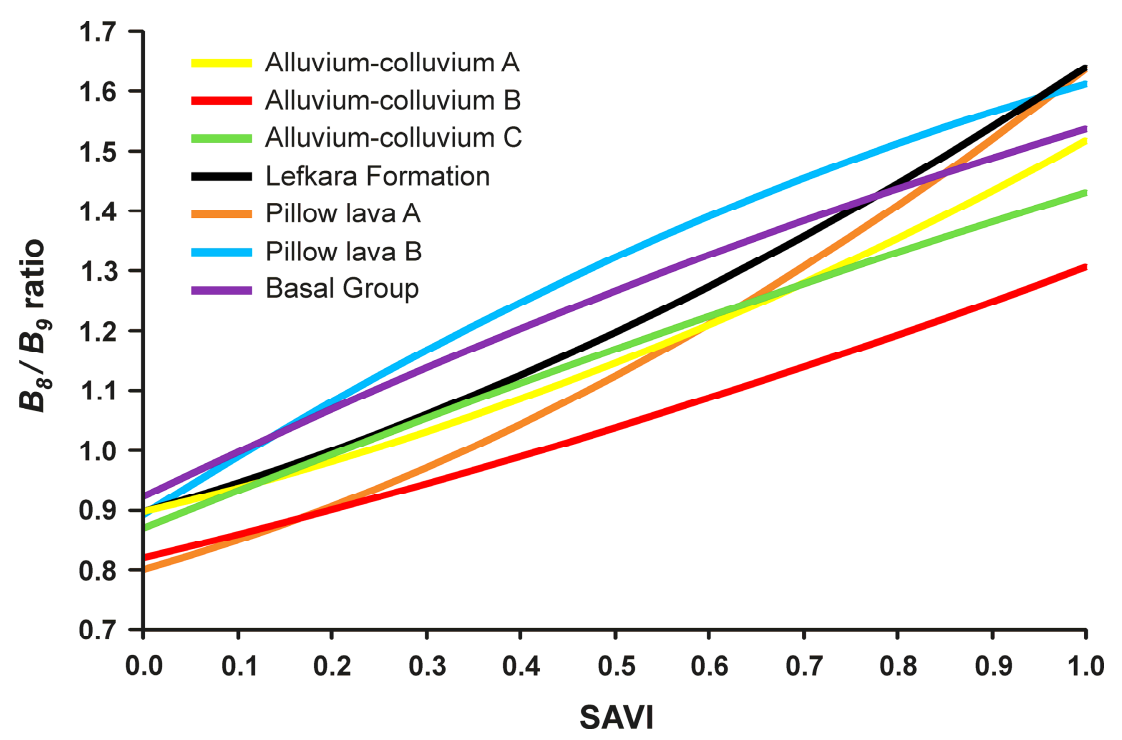

The responses of the ATM $B_{8} / B$ 9 band ratios to increasing SAVI (Figure 9) show marked similarities to those predicted by synthetically mixing the lithologies with dry grass. Concurrent with the modeled responses (see Figure 8b), the moderate-to-high albedo lithologies (i.e., "Alluvium-colluvium A", Lefkara Formation, PLA) exhibit concave-up curvilinear responses in $B 8 / B 9$ for increasing fractional cover, whereas the remaining low-to-moderate albedo units exhibit linear or slightly concave-down responses. Despite this, the impact of dry grass in the imagery seems to be slightly greater than predicted, with obscuring of the lithologies occurring for $15 \%$ less fractional cover, on average, than their theoretical responses. Such relatively minor deviations could be due to noise in the data [26], or due the influence of non-dry grass vegetation on both the ATM $B_{8} / B_{9}$ band ratio and SAVI. Although spectral unmixing of the ATM imagery could potentially be used to extract accurate sub-pixel abundances of each specific vegetation type, rigorous application of this technique was hindered by the lack of representative spectral end-members for some of the minor scene constituents (e.g., roads, mine spoil heap, buildings, trees). Nevertheless, the overall agreement indicates that the theoretical effects of vegetation determined using synthetic spectral mixing analysis are representative of those in the imagery.

\subsection{Impact of Vegetation on Remote Lithological Mapping}

Lithological classification of the calibrated ATM multispectral imagery was undertaken in conjunction with the ATM-convolved spectral signatures shown in Figure 4. Following classification, pixels matching each reference spectrum were grouped according to the four main lithologies. The three lithological maps generated using the SAM, MF and SFF classification algorithms are shown in 
Figure $10 \mathrm{a}-\mathrm{c}$, respectively. The corresponding overall and individual lithological class accuracies associated with these maps are summarized in the confusion matrices shown in Table 2.

Figure 10. Lithological maps generated using the (a) Spectral Angle Mapper (SAM), (b) Matched Filtering (MF) and (c) Spectral Feature Fitting (SFF) classification algorithms.
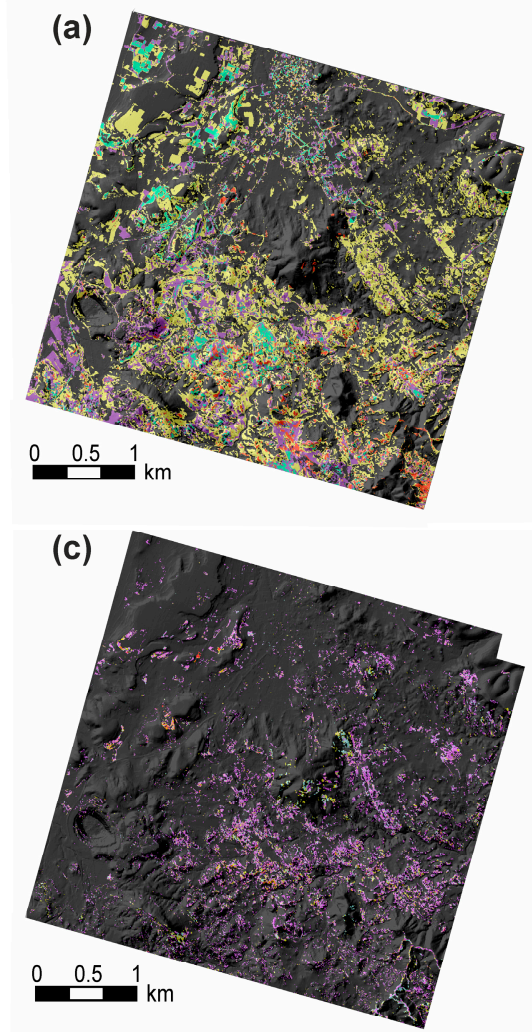
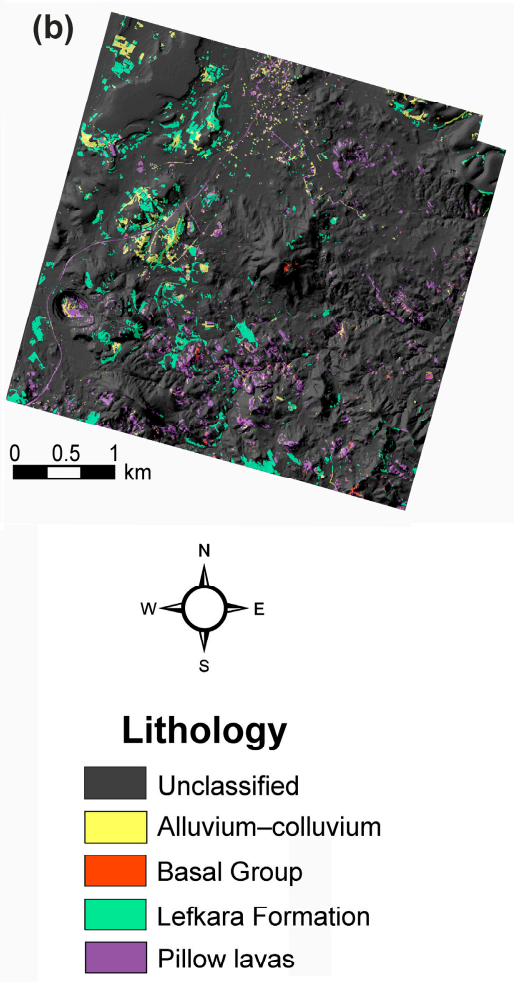

Table 2. Confusion matrices for the lithological maps derived using the SAM, MF and SFF algorithms. AC, Alluvium-colluvium; BG, Basal Group; LF, Lefkara Formation; PL, pillow lavas; UA, user's accuracy, PA, producer's accuracy; K, Kappa coefficient.

\begin{tabular}{|c|c|c|c|c|c|c|}
\hline \multirow{2}{*}{$\begin{array}{l}\text { SAM } \\
\text { Mapped as }\end{array}$} & \multicolumn{4}{|c|}{ Validation Data } & \multirow{2}{*}{ Row Total } & \multirow{2}{*}{ UA (\%) } \\
\hline & $\mathbf{A C}$ & BG & $\mathbf{L F}$ & PL & & \\
\hline Unclassified & 3299 & 2544 & 1969 & 1875 & 9687 & - \\
\hline $\mathrm{AC}$ & 589 & 542 & 393 & 1046 & 2570 & 22.9 \\
\hline BG & 1 & 61 & 12 & 93 & 167 & 36.5 \\
\hline LF & 34 & 2 & 50 & 52 & 138 & 36.2 \\
\hline PL & 164 & 51 & 27 & 142 & 384 & 37.0 \\
\hline Column total & 4087 & 3200 & 2451 & 3208 & & \\
\hline PA (\%) & 14.4 & 1.9 & 2.0 & 4.4 & & \\
\hline \multicolumn{7}{|c|}{ Overall accuracy $=6.5 \%$} \\
\hline
\end{tabular}


Table 2. Cont.

\begin{tabular}{|c|c|c|c|c|c|c|}
\hline \multirow{2}{*}{$\begin{array}{l}\text { MF } \\
\text { Mapped as }\end{array}$} & \multicolumn{4}{|c|}{ Validation Data } & \multirow{2}{*}{ Row Total } & \multirow{2}{*}{$\begin{array}{l}\text { UA } \\
(\%)\end{array}$} \\
\hline & $\mathbf{A C}$ & BG & $\mathbf{L F}$ & PL & & \\
\hline Unclassified & 4006 & 3052 & 2315 & 2960 & 12333 & - \\
\hline $\mathrm{AC}$ & 31 & 0 & 65 & 21 & 117 & 26.5 \\
\hline $\mathrm{BG}$ & 0 & 0 & 0 & 17 & 17 & 0.0 \\
\hline LF & 50 & 84 & 67 & 0 & 201 & 33.3 \\
\hline PL & 0 & 64 & 4 & 210 & 278 & 75.5 \\
\hline Column total & 4087 & 3200 & 2451 & 3208 & & \\
\hline $\mathrm{PA}(\%)$ & 0.8 & 0.0 & 2.7 & 6.5 & & \\
\hline \multicolumn{7}{|c|}{$\begin{array}{l}\text { Overall accuracy }=2.4 \% \\
\mathrm{~K}=0.01\end{array}$} \\
\hline \multirow{2}{*}{$\begin{array}{l}\text { SFF } \\
\text { Mapped as }\end{array}$} & \multicolumn{4}{|c|}{ Validation Data } & \multirow{2}{*}{ Row Total } & \multirow{2}{*}{$\begin{array}{l}\text { UA } \\
(\%)\end{array}$} \\
\hline & $\mathrm{AC}$ & BG & $\mathbf{L F}$ & $\mathbf{P L}$ & & \\
\hline Unclassified & 3964 & 3947 & 2445 & 2690 & 12046 & - \\
\hline $\mathrm{AC}$ & 10 & 65 & 0 & 79 & 154 & 6.5 \\
\hline $\mathrm{BG}$ & 1 & 1 & 0 & 1 & 3 & 33.3 \\
\hline LF & 16 & 49 & 3 & 100 & 168 & 1.8 \\
\hline PL & 96 & 138 & 3 & 338 & 575 & 58.8 \\
\hline Column total & 4087 & 3200 & 2451 & 3208 & & \\
\hline $\mathrm{PA}(\%)$ & 0.2 & 0.0 & 0.1 & 10.5 & & \\
\hline \multicolumn{7}{|c|}{ Overall accuracy $=2.7 \%$} \\
\hline
\end{tabular}

The overall accuracy statistics suggest that all three algorithms result in the generation of inaccurate maps, with the SAM algorithm achieving the highest overall accuracy $(6.5 \%)$, followed by SFF (2.7\%) and MF (2.4\%). The poor performance is corroborated by values of $\sim 0.00$ for the Kappa coefficient (K), which indicate that these results could easily be achieved through random classifications [76]. Although partially attributable to confusion between inherently similar lithologies (e.g., alluvium-colluvium and its parent rocks), the low user's and producer's accuracies for all algorithms are heavily influenced by the vast proportion of unclassified validation pixels. The proportion of validation pixels left unclassified in each of the three classifications is $75 \%-95 \%$, which is also mirrored throughout the entire study area with $66 \%-92 \%$ of all scene pixels remaining unclassified. Only a relatively minor proportion of these unclassified pixels can be accounted for by the occurrence of non-lithological surface materials (e.g., mine spoil, roads, buildings). In all three cases, the proportion of unclassified pixels could be reduced by adjusting the classification threshold values that were used to extract closely matching pixels. For instance, in the case of the SAM algorithm, the mapping results could potentially be improved somewhat by defining the angle threshold for each reference spectrum separately [77]. However, achieving a considerable reduction in the proportion of unclassified pixels would require significant relaxation of the thresholds, which will undoubtedly further increase the confusion between classes and decrease the overall accuracy. Note that the readiness of the SAM algorithm to classify a relatively high proportion of pixels, albeit incorrectly, suggests that the angle threshold is already too low in this instance. 
Table 3. SAVI statistics and statistical difference in SAVI between classified and unclassified pixels as determined using the unequal variance t-test.

\begin{tabular}{|c|c|c|c|c|c|c|c|c|}
\hline & \multirow[b]{2}{*}{ Classifier } & \multicolumn{3}{|c|}{ Classified } & \multicolumn{3}{|c|}{ Unclassified } & \multirow{2}{*}{$p$-value } \\
\hline & & $\mathbf{n}$ & Mean & SD & $\mathbf{n}$ & Mean & SD & \\
\hline \multirow[t]{3}{*}{ Validation pixels } & SAM & 3259 & 0.30 & 0.13 & 9687 & 0.67 & 0.19 & $<0.0001$ \\
\hline & $\mathrm{MF}$ & 613 & 0.23 & 0.15 & 12,333 & 0.59 & 0.23 & $<0.0001$ \\
\hline & SFF & 900 & 0.29 & 0.11 & 12,046 & 0.60 & 0.23 & $<0.0001$ \\
\hline \multirow[t]{3}{*}{ All scene pixels } & SAM & 259,230 & 0.27 & 0.13 & 498,570 & 0.63 & 0.22 & $<0.0001$ \\
\hline & $\mathrm{MF}$ & 78,089 & 0.20 & 0.18 & 679,711 & 0.54 & 0.24 & $<0.0001$ \\
\hline & SFF & 57,279 & 0.26 & 0.11 & 700,521 & 0.53 & 0.26 & $<0.0001$ \\
\hline
\end{tabular}

A visually perceived spatial correlation between high SAVI values and unclassified pixels in the scene can be confirmed statistically (Table 3), suggesting that the large number of unclassified pixels is linked to the obscuring effects of vegetation cover. To investigate this further, ATM $B_{8} / B 9$ band ratio and SAVI values were analyzed for a random sample of scene pixels classified as one of the four lithologies using the SFF and MF algorithms (Figure 11). Whereas unclassified pixels in the SFF-derived map have a large range of $0.4-3.9$ in $B 8 / B 9$, classified pixels correspond to $B 8 / B 9$ values of $<1.0$ (Figure 11a). This is explicable because SFF is a direct spectral matching classifier, and the results of the synthetic spectral mixing analysis reveal that the spectra of the lithologies are significantly obscured at $B 8 / B 9$ values $\geq 1.0$. The maximum SAVI values for each lithology indicate the fractional abundances above which spectral recognition is no longer possible due to obscuring and masking by dry grassy cover. The fractional abundance limits for the four lithologies are consistent with those predicted through synthetic spectral mixing analysis. Again, this is expected because SFF is a direct spectral matching technique and the spectra of the lithologies are no longer recognizable above these abundances. In comparison, the MF algorithm appears capable of classifying pixels with $B_{8} / B_{9}$ values of $>1.0$ and higher abundances of dry grasses (Figure 11b). On average, the maximum fractional abundances are $25 \%$ higher than those associated with the SFF algorithm, with classification of the Lefkara Formation, alluvium-colluvium and pillow lavas still possibly for cover $\geq 70 \%$. The enhanced capability of the MF algorithm is due to its ability to partially unmix the composite spectra to separate the contribution of vegetation from that of the underlying lithology. Despite this added potential, the MF map does contain a higher number of unclassified pixels than the SAM-derived map (Table 3). Although classifying more conservatively, the MF algorithm outperforms both the SAM $(25.8 \% ; \mathrm{K}=0.00)$ and SFF $(39.1 \% ; \mathrm{K}=0.00)$ algorithms considerably in terms of overall mapping accuracy, assigning $50.2 \%(\mathrm{~K}=0.30)$ of the classified validation pixels to the correct lithology. When unclassified pixels are excluded from the analysis, the primary source of error in the MF map is due to confusion between alluvium-colluvium and its parent rock types, as well as the inability to correctly classify any Basal Group validation pixels (see Table 2). 
Figure 11. Impact of dry grassy vegetation abundance (SAVI) on the ability of the (a) SFF and (b) MF algorithms to classify pixels in the ATM imagery.

(a)

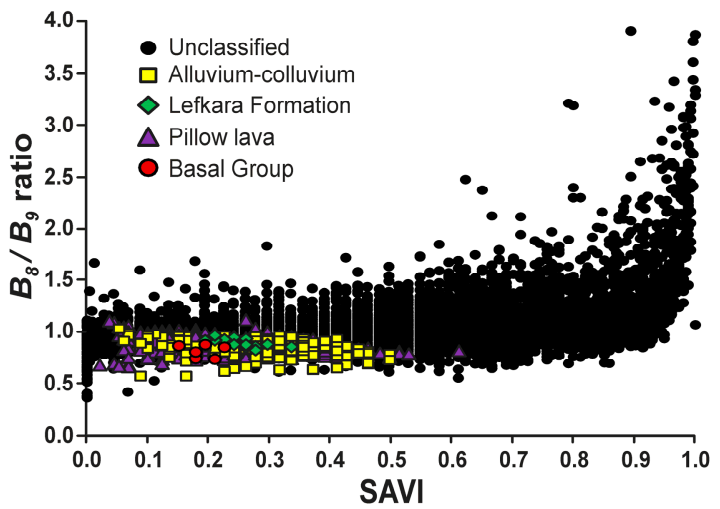

(b)

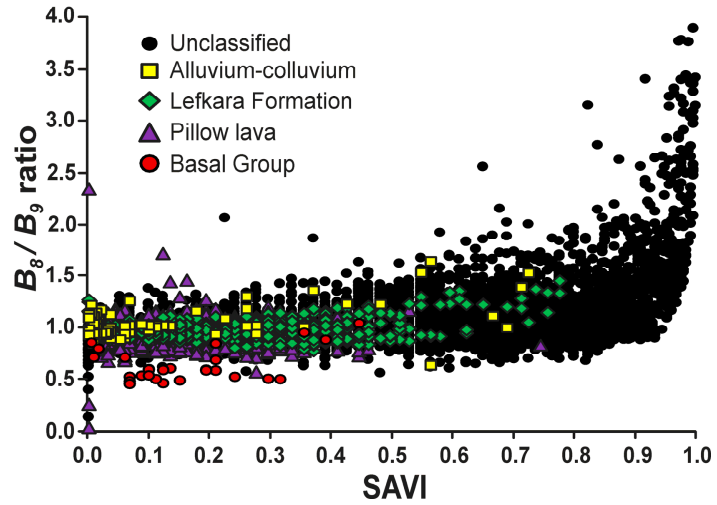

Figure 12. Comparison of the remote lithological mapping capabilities of the MF algorithm with observation made in the field.

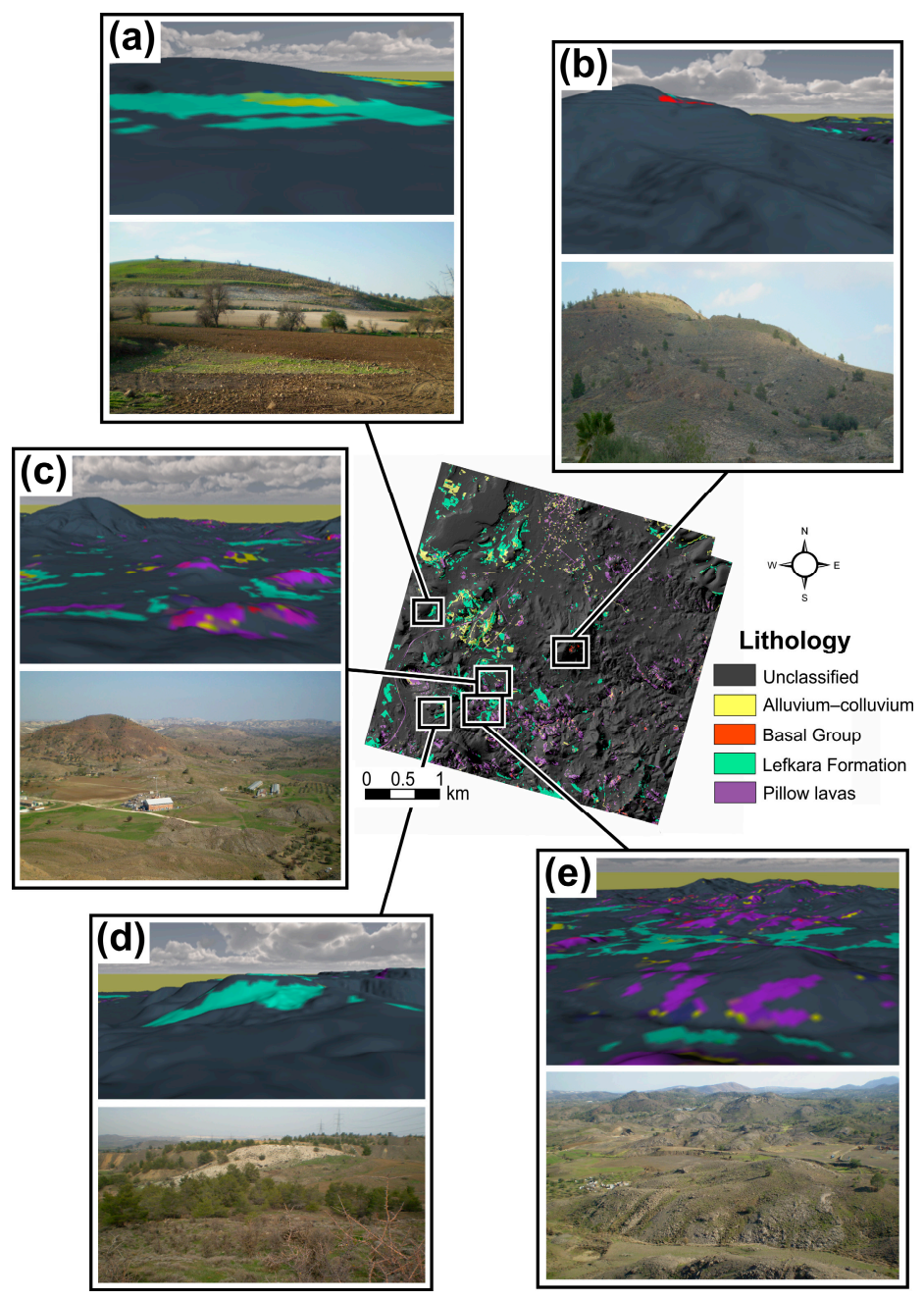

Considering the results obtained using the optimal MF algorithm alongside field observations enables a more comprehensive understanding of the mapping capabilities and limitations. Evidence of confusion between alluvium-colluvium and its parent rock types is apparent throughout the study area, 
particularly for alluvium-colluvium and the Lefkara Formation in areas with low relief (Figure 12a,e). This confusion is due to the inherent spectral similarity between the two units. Despite appearing to be largely bare and unclassified in Figure 12a, the darker alluvium-colluvium soils were actually being used to grow crops at the time of the airborne survey. In agreement with the synthetic spectral mixing results, the MF algorithm successfully maps larger (higher relief) Lefkara Formation outcrops with less than $70 \%$ of predominantly grass cover (Figure 12d), while failing to map those with cover above this threshold (Figure 12a). None of the Basal Group validation pixels were correctly identified due to fractional dry grassy cover typically exceeding $45 \%$ at the pixel scale (i.e., $4 \mathrm{~m}$ ) $-45 \%$ corresponding to MF classification threshold for this lithology (see Figure 11b). However, a small cluster of Basal Group pixels not included in the validation dataset have been correctly mapped near the summit of the main central outcrop as a result of them becoming completely exposed through small-scale quarrying (Figure 12b). The spatial distribution of the pillow lavas is poorly mapped because field observations reveal that combined lichen and green-dry grass fractional cover commonly exceeds $70 \%$. The MF algorithm is, however, capable of mapping sizeable proportions of pillow lava outcrops where vegetation cover is less than $70 \%$ at the pixel scale (Figure 12c,e).

Overall, the impact of vegetation on spectral recognition and remote lithological mapping, elucidated here using a combination of spectral mixing and image analysis, is consistent with observations made in the field. From the results presented, it is evident that direct spectral identification of the lithological units in the ATM imagery is primarily controlled by the abundance of fractional vegetation cover. Vegetation abundance in the study areas regularly exceeds the limits above which spectral recognition of the lithologies is possible, thus accounting for the vast proportions of unclassified pixels in the derived maps. Nevertheless, it has been shown that it is possible to extract some useful lithological information from the ATM imagery provided that an appropriate technique is employed. Enhanced mapping of the spatial distribution of the lithologies in highly vegetated areas may be possible if geobotanical relationships with the underlying substrates are realized and the vegetation spectra used as proxies [12,14,78]. Indeed, for this same study area, Grebby et al. [34] exploited geobotanical relationships in conjunction with an artificial neural network classifier to produce an accurate $(65.5 \% ; \mathrm{K}=0.54)$ lithological map with well-defined contacts and contiguous spatial coverage.

\section{Conclusions}

This case study elucidates the impact of vegetation cover on the ability to use airborne multispectral imagery for direct identification and mapping of geological substrates in an area of the Troodos ophiolite, Cyprus. The impact of green and dry grass, and lichen on spectral recognition of the lithologies was determined through synthetic linear spectral mixing analysis. Green grass was found to impart a characteristic chlorophyll absorption feature at $0.65-0.70 \mu \mathrm{m}$, along with moderate and high reflectance peaks at $0.55 \mu \mathrm{m}$ and $0.80-0.90 \mu \mathrm{m}$, respectively. These features were found to significantly obscure low albedo lithologies at 30\%-40\% fractional green grass abundance, and $50 \%-65 \%$ and $75 \%$ for the moderate and high albedo lithologies, respectively. The obscuring effects of dry grass were found to be more significant than those of green grass, with the spectra of most lithologies obscured for $20 \%-40 \%$ fractional cover. In agreement with previous studies, the obscuring effect of lichen cover 
was found to be dependent on the spectral contrast between the lithology and lichen for a given wavelength range. Lithologies with higher spectral contrast in the $0.60-0.70 \mu \mathrm{m}$ range were somewhat obscured by as little as $30 \%$ fractional lichen cover, compared to $50 \%$ for the lithology with low spectral contrast. Complete masking of the spectra of all lithologies occurred at $50 \%-70 \%$ lichen cover. The impact of dry grass abundance on spectral recognition of the lithologies in the ATM imagery was determined, thus confirming the relevance of the theoretical results modeled through synthetic mixing analysis.

Lithological maps produced through classification of the ATM imagery in conjunction with the bare rock/soil spectra contained relatively little information on the spatial distribution of the lithologies, with $66 \%-92 \%$ of all scene pixels remaining unclassified. A correlation between the unclassified pixels and higher fractional vegetation abundances was confirmed quantitatively using an ATM-derived SAVI map. The maximum vegetation abundances above which pixel classification was no longer possible were established for the SFF- and MF-derived maps. The maximum vegetation abundances associated with the direct spectral matching SFF algorithm were consistent with those determined theoretically for each lithology. The corresponding abundances for the MF algorithm were $25 \%$ higher on average, which is a reflection of its ability to partially unmix the composite spectra to separate the contribution of vegetation from that of the underlying lithology. The mapping capabilities of the MF algorithm were further corroborated with field observations.

Despite the limited spectral sampling and spectral resolution of the ATM sensor and the significant obscuring effects of the relatively dense, ubiquitous vegetation cover, this study highlights that lithological information can be extracted from the imagery with the aid of an appropriate mapping algorithm. In this case, the MF classification algorithm outperformed the direct spectral matching SAM and SFF algorithms because of its ability to partially unmix target spectra for pixels with higher sub-pixel vegetation abundances. It is anticipated that hyperspectral imagery with higher spectral and spatial resolution, application of spectral unmixing techniques, or use of reference spectra corresponding to rock-vegetation mixtures may yield better results in terms of contiguous mapping of the spatial distribution of the lithologies. The $B_{3} / B_{5}, B_{8} / B_{9}$ and $B_{5} / B_{4}$ ratios enable differentiation between green grass, dry grass and lichen, and, more importantly, their modeled responses to vegetation abundance could also prove useful in helping to extract more lithological information, especially for high proportions of vegetation cover.

In summary, the results of this study provide useful insights to the potential capabilities and challenges faced when utilizing comparable sensors - such as those on-board the Landsat 8, Sentinel-2 and WorldView-3 satellites - to map similar types of terrain. Careful consideration of the outcomes of both similar and contrasting case studies can ultimately help identify the most appropriate combination of sensor, platform and classification algorithm for mapping any given location, within the available budget.

\section{Acknowledgments}

This work was supported by a Natural Environment Research Council (NERC) CASE Studentship (NE/F00673X/1) with the British Geological Survey (BGS), awarded to Stephen Grebby. We gratefully acknowledge the NERC Airborne Research and Survey Facility (MC04/30) for ATM data acquisition, and the NERC Field Spectroscopy Facility (loan No: 589.1209) and Alasdair MacArthur 
for loan of and advice on using the ASD FieldSpec ${ }^{\circledR}$ Pro. We also express our gratitude to the Geological Survey Department of Cyprus (GSD) for providing the digital geology data, to Stelios Nicolaides (GSD) and Simon Jowitt (Monash University) for invaluable logistical and scientific help in the field, and to Luke Bateson (BGS) for AZGCORR software support. Stephen Grebby is grateful to the Geological Remote Sensing Group for a Student Fieldwork and Travel Award. The five anonymous reviewers are thanked for their comments and suggestions which helped to improve the manuscript. Stephen Grebby and Jonathan Naden publish with permission of the executive director, British Geological Survey (NERC).

\section{Author Contributions}

Stephen Grebby designed the study, processed the airborne data and spectroscopic measurements, and conducted the analysis. All authors were involved in reconnaissance and validation fieldwork, and provided crucial input appropriate to their expertise. The manuscript was written by Stephen Grebby with contributions from all authors.

\section{Conflicts of Interest}

The authors declare no conflict of interest.

\section{References}

1. Hunt, G.R. Spectral signatures of particulate minerals in visible and near infrared. Geophysics 1977, 42, 501-513.

2. Rothery, D.A. Improved discrimination of rock units using Landsat Thematic Mapper imagery of the Oman ophiolite. J. Geol. Soc. 1987, 144, 587-597.

3. van der Meer, F.D.; van der Werff, H.M.A.; van Ruitenbeek, F.J.A.; Hecker, C.A.; Bakker, W.H.; Noomen, M.F.; van der Meijde, M.; Carranza, E.J.M.; de Smeth, J.B.; Woldai, T. Multi- and hyperspectral geologic remote sensing: A review. Int. J. Appl. Earth Obs. Geoinf. 2012, 14, 112-128.

4. Hunt, G.R.; Salisbury, J.W. Visible and near infrared spectra of minerals and rocks: I Silicate minerals. Mod. Geol. 1970, 1, 283-300.

5. Hunt, G.R.; Salisbury, J.W. Visible and near infrared spectra of minerals and rocks: II Carbonates. Mod. Geol. 1971, 2, 23-30.

6. Hunt, G.R.; Salisbury, J.W.; Lenhoff, J.C. Visible and near-infrared spectra of minerals and rocks: IV Sulphides and sulphates. Mod. Geol. 1971, 3, 1-14.

7. Hunt, G.R.; Salisbury, J.W.; Lenhoff, J.C. Visible and near-infrared spectra of minerals and rocks: V Halides, phosphates, arsenates, vanadates and borates. Mod. Geol. 1972, 3, 121-132.

8. Adams, J.B. Visible and near-infrared diffuse reflectance spectra of pyroxenes as applied to remote-sensing of solid objects in solar-system. J. Geophys. Res. 1974, 79, 4829-4836.

9. Clark, R.N.; King, T.V.V.; Klejwa, M.; Swayze, G.A.; Vergo, N. High spectral resolution reflectance spectroscopy of minerals. J. Geophys. Res. 1990, 95, 12653-12680. 
10. van der Meer, F.; Vazquez-Torres, M.; van Dijk, P.M. Spectral characterization of ophiolite lithologies in the Troodos Ophiolite complex of Cyprus and its potential in prospecting for massive sulphide deposits. Int. J. Remote Sens. 1997, 18, 1245-1257.

11. Rowan, L.C.; Mars, J.C. Lithologic mapping in the Mountain Pass, California area using advanced Spaceborne thermal emission and reflection radiometer (ASTER) data. Remote Sens. Environ. 2003, 84, 350-366.

12. Rowan, L.C.; Simpson, C.J.; Mars, J.C. Hyperspectral analysis of the ultramafic complex and adjacent lithologies at Mordor, NT, Australia. Remote Sens. Environ. 2004, 91, 419-431.

13. Rowan, L.C.; Mars, J.C.; Simpson, C.J. Lithologic mapping of the Mordor, NT, Australia ultramafic complex by using the Advanced Spaceborne Thermal emission and Reflection Radiometer (ASTER). Remote Sens. Environ. 2005, 99, 105-126.

14. Harris, J.R.; Rogge, D.; Hitchcock, R.; Ijewliw, O.; Wright, D. Mapping lithology in Canada's Arctic: Application of hyperspectral data using the minimum noise fraction transformation and matched filtering. Can. J. Earth Sci. 2005, 42, 2173-2193.

15. Bedini, E. Mapping lithology of the Sarfartoq carbonatite complex, southern West Greenland, using HyMap imaging spectrometer data. Remote Sens. Environ. 2009, 113, 1208-1219.

16. Roy, R.; Launeau, P.; Carrere, V.; Pinet, P.; Ceuleneer, G.; Clenet, H.; Daydou, Y.; Girardeau, J.; Amri, I. Geological mapping strategy using visible near-infrared-shortwave infrared hyperspectral remote sensing: Application to the Oman ophiolite (Sumail Massif). Geochem. Geophy. Geosy. 2009, 10, doi:10.1029/2008GC002154.

17. Haselwimmer, C.E.; Riley, T.R.; Liu, J.G. Assessing the potential of multispectral remote sensing for lithological mapping on the Antarctic Peninsula: Case study from eastern Adelaide Island, Graham Land. Antarct. Sci. 2010, 22, 299-318.

18. Tangestani, M.H.; Jaffari, L.; Vincent, R.K.; Sridhar, B.B.M. Spectral characterization and ASTER-based lithological mapping of an ophiolite complex: A case study from Neyriz ophiolite, SW Iran. Remote Sens. Environ. 2011, 115, 2243-2254.

19. van der Meer, F.D.; van der Werff, H.M.A.; van Ruitenbeek, F.J.A. Potential of ESA's Sentinel-2 for geological applications. Remote Sens. Environ. 2014, 148, 124-133.

20. Fraser, S.J.; Green, A.A. A software defoliant for geological analysis of band ratios. Int. J. Remote Sens. 1987, 8, 525-532.

21. Carranza, E.J.M.; Hale, M. Mineral imaging with Landsat Thematic Mapper data for hydrothermal alteration mapping in heavily vegetated terrane. Int. J. Remote Sens. 2002, 23, 4827-4852.

22. Siegal, B.S.; Goetz, A.F.H. Effect of vegetation on rock and soil type discrimination. Photogramm. Eng. Remote Sens. 1977, 43, 191-196.

23. Murphy, R.J.; Wadge, G. The effects of vegetation on the ability to map soils using imaging spectrometer data. Int. J. Remote Sens. 1994, 15, 63-86.

24. Ager, C.M.; Milton, N.M. Spectral reflectance of lichens and their effects on the reflectance of rock substrates. Geophysics 1987, 52, 898-906.

25. Crippen, R.E.; Blom, R.G. Unveiling the lithology of vegetated terrains in remotely sensed imagery. Photogramm. Eng. Remote Sens. 2001, 67, 935-943. 
26. Bierwirth, P.N. Mineral mapping and vegetation removal via data-calibrated pixel unmixing, using multispectral. Int. J. Remote Sens. 2009, 11, 1999-1207.

27. Chabrillat, S.; Pinet, P.C.; Ceuleneer, G.; Johnson, P.E.; Mustard, J.F. Ronda peridotite massif: Methodology for its geological mapping and lithological discrimination from airborne hyperspectral data. Int. J. Remote Sens. 2000, 21, 2363-2388.

28. Asner, G.P.; Heidebrecht, K.B. Spectral unmixing of vegetation, soil and dry carbon cover in arid regions: Comparing multispectral and hyperspectral observations. Int. J. Remote Sens. 2002, 23, 3939-3958.

29. Zhang, J.; Rivard, B.; Sanchez-Azofeifa, A. Spectral unmixing of normalized reflectance data for the deconvolution of lichen and rock mixtures. Remote Sens. Environ. 2005, 95, 57-66.

30. Morison, M.; Cloutis, E.; Mann, P. Spectral unmixing of multiple lichen species and underlying substate. Int. J. Remote Sens. 2014, 35, 478-492.

31. Rogge, D.; Rivard, B.; Segl, K.; Grant, B.; Feng, J. Mapping of NiCu-PGE ore hosting ultramafic rocks using airborne and simulated EnMAP hyperspectral imagery, Nunavik, Canada. Remote Sens. Environ. 2014, 152, 302-317.

32. Schetselaar, E.M.; Chung, C.J.F.; Kim, K.E. Integration of Landsat TM, gamma-ray, magnetic, and field data to discriminate lithological units in vegetated granite-gneiss terrain. Remote Sens. Environ. 2000, 71, 89-105.

33. Dong, P.; Leblon, B. Rock unit discrimination on Landsat TM, SIR-C and Radarsat images using spectral and textural information. Int. J. Remote Sens. 2004, 25, 3745-3768.

34. Grebby, S.; Naden, J.; Cunningham, D.; Tansey, K. Integrating airborne multispectral imagery and airborne LiDAR data for enhanced lithological mapping in vegetated terrain. Remote Sens. Environ. 2011, 115, 214-226.

35. Rodger, A.; Cudahy, T. Vegetation corrected continuum depths at $2.20 \mu \mathrm{m}$ : An approach for hyperspectral sensors. Remote Sens. Environ. 2009, 113, 2243-2257.

36. Haest, M.; Cudahy, T.; Rodger, A.; Laukamp, C.; Martens, E.; Caccetta, M. Unmixing the effects of vegetation in airborne hyperspectral mineral maps over the Rocklea Dome iron-rich palaeochannel system (Western Australia). Remote Sens. Environ. 2013, 129, 17-31.

37. Satterwhite, M.B.; Henley, J.P.; Carney, J.M. Effects of lichens on the reflectance spectra of granitic rock surfaces. Remote Sens. Environ. 1985, 18, 105-112.

38. Rivard, B.; Arvidson, R.E. Utility of imaging spectrometry for lithologic mapping in Greenland. Photogramm. Eng. Remote Sens. 1992, 58, 945-949.

39. Feng, J.; Rivard, B.; Rogge, D.; Sanchez-Azofeifa, A. The longwave infrared (3-14 $\mu \mathrm{m})$ spectral properties of rock encrusting lichens based on laboratory spectra and airborne SEBASS imagery. Remote Sens. Environ. 2013, 131, 173-181.

40. Gass, I.G. Is the troodos massif of Cyprus a fragment of mesozoic ocean crust? Nat. 1968, 220, 39-42.

41. Moores, E.M.; Vine, F.J. Troodos Massif, Cyprus and other ophiolites as oceanic crust: Evaluation and implications. Philos. T. R. Soc. A 1971, 268, 443-467.

42. Varga, R.J.; Moores, E.M. Spreading structure of the Troodos ophiolite, Cyprus. Geology 1985, $13,846-850$. 
43. Gass, I.G. The Geology and Mineral Resources of the Dhali Area; Geological Survey Department: Lefkosia, Cyprus, 1960.

44. Grebby, S.; Cunningham, D.; Naden, J.; Tansey, K. Lithological mapping of the Troodos ophiolite, Cyprus, using airborne LiDAR topographic data. Remote Sens. Environ. 2010, 114, 713-724.

45. Grebby, S.; Cunningham, D.; Naden, J.; Tansey, K. Application of airborne LiDAR data and airborne multispectral imagery to structural mapping of the upper section of the Troodos ophiolite, Cyprus. Int. J. Earth Sci. 2012, 101, 1645-1660.

46. Kruse, F.A.; Lefkoff, A.B.; Boardman, J.W.; Heidebrecht, K.B.; Shapiro, A.T.; Barloon, P.J.; Goetz, A.F.H. The Spectral Image-Processing System (SIPS)-Interactive visualization and analysis of imaging spectrometer data. Remote Sens. Environ. 1993, 44, 145-163.

47. Singer, R.B.M.; McCord, T.B. Mars: Large scale mixing of bright and dark surface materials and implications for analysis of spectral reflectance. In Proceedings of the 10th Lunar and Planetary Science Conference, Houston, TX, USA, 19-23 March 1979; Pergamon Press, Inc.: New York, NY, USA; pp. 1835-1848.

48. Roberts, D.A.; Yamaguchi, Y.; Lyon, R.J.P. Calibration of airborne imaging spectrometer data to percent reflectance using field spectral measurements. In Proceedings of 19th International Symposium on Remote Sensing of Environment, Ann Arbor, MI, USA, 21 October 1985; pp. 679-688.

49. Baugh, W.M.; Groeneveld, D.P. Empirical proof of the empirical line. Int. J. Remote Sens. 2008, 29, 665-672.

50. Ferrier, G. Evaluation of apparent surface reflectance estimation methodologies. Int. J. Remote Sens. 1995, 16, 2291-2297.

51. van der Meer, F.; Bakker, W. Cross correlogram spectral matching: application to surface mineralogical mapping by using AVIRIS data from Cuprite, Nevada. Remote Sens. Environ. 1997, 61, 371-382.

52. Price, J.C.; Anger, C.D.; Mah, S. Preliminary evaluation of casi preprocessing techniques. In Proceedings of the 17th Canadian Symposium on Remote Sensing, Saskatoon, SK, Canada, 13-15 June 1995; Canadian Remote Sensing Society and Canadian Aeronautics and Space Institute: Ontario, ON, Canada; pp. 649-697.

53. Smith, G.M.; Milton, E.J. The use of the empirical line method to calibrate remotely sensed data to reflectance. Int. J. Remote Sens. 1999, 20, 2653-2662.

54. Harsanyi, J.C.; Chang, C.I. Hyperspectral image classification and dimensionality reduction-An orthogonal subspace projection approach. IEEE Trans. Geosci. Remote Sens. 1994, 32, 779-785.

55. Green, A.A.; Berman, M.; Switzer, P.; Craig, M.D. A transformation for ordering multispectral data in terms of image quality with implications for noise removal. IEEE Trans. Geosci. Remote Sens. 1988, 26, 65-74.

56. Mundt, J.; Streutker, D.; Glenn, N. Partial unmixing of hyperspectral imagery: Theory and methods. In Proceedings of the American Society for Photogrammetry and Remote Sensing, Tampa, FL, USA, 7-11 May 2007.

57. Mitchell, J.J.; Glenn, N.F. Subpixel abundance estimates in mixture-tuned matched filtering classifications of leafy spurge (Euphorbia esula L.). Int. J. Remote Sens. 2009, 30, 6099-6119. 
58. Clark, R.N.; Gallagher, A.J.; Swayze, G.A. Material absorption band depth mapping of imaging spectrometer data using the complete band shape least squares algorithm simultaneously fit to multiple spectral features from multiple materials. In Proceedings of the Second Airborne Visible/Infrared Imaging Spectrometer (AVIRIS) Workshop, Pasadena, CA, USA, 4-5 June 1990; pp. 176-186.

59. Clark, R.N.; Swayze, G.A.; Gallagher, A.; Gorelick, N.; Kruse, F.A. Mapping with imaging spectrometer data using the complete band shape least-squares algorithm simultaneously fit to multiple spectral features from multiple materials. In Proceedings of the Third Airborne Visible/Infrared Imaging Spectrometer (AVIRIS) Workshop, Pasadena, CA, USA, 20-21 May 1991; pp. 2-3.

60. Clark, R.N.; Swayze, G.A.; Gallagher, A. Mapping the mineralogy and lithology of Canyonlands, Utah with imaging spectrometer data and the multiple spectral feature mapping algorithm. In Proceedings of the Third Annual JPL Airborne Geoscience Workshop, Pasadena, CA, USA, 1-5 June 1992; pp. 11-13.

61. Clark, R.N.; Roush, T.L. Reflectance spectroscopy-Quantitative analysis techniques for remote-sensing applications. J. Geophys. Res. 1984, 89, 6329-6340.

62. Clark, R.N.; Swayze, G.A.; Livo, K.E.; Kokaly, R.F.; Sutley, S.J.; Dalton, J.B.; McDougal, R.R.; Gent, C.A. Imaging spectroscopy: Earth and planetary remote sensing with the USGS Tetracorder and expert systems. J. Geophys. Res. Planet. 2003, 108, doi:10.1029/2002JE001847.

63. Crowley, J.K.; Williams, D.E.; Hammarstrom, J.M.; Piatak, N.; Chou, I-M.; Mars, J.C. Spectral reflectance properties $(0.4-2.5 \mu \mathrm{m})$ of secondary Fe-oxide, Fe-hydroxide, and Fe-sulphate-hydrate minerals associated with sulphide-bearing mine wastes. Geochem. Explor. Environ. Anal. 2003, 3, 219-228.

64. Congalton, R.G. A review of assessing the accuracy of classifications of remotely sensed data. Remote Sens. Environ. 1991, 37, 35-46.

65. Chini, M.; Pacifici, F.; Emery, W.J.; Pierdicca, N.; Del Frate, F. Comparing statistical and neural network methods applied to very high resolution satellite images showing changes in man-made structures at rocky flats. IEEE Trans. Geosci. Remote Sens. 2008, 46, 1812-1821.

66. Pacifici, F.; Chini, M.; Emery, W.J. A neural network approach using multi-scale textural metrics from very high-resolution panchromatic imagery for urban land-use classification. Remote Sens. Environ. 2009, 113, 1276-1292.

67. Huete, A.R. A soil-adjusted vegetation index (SAVI). Remote Sens. Environ. 1988, 25, 295-309.

68. Leprieur, C.; Verstraete, M.M.; Pinty, B. Evaluation of the performance of various vegetation indices to retrieve vegetation cover from AVHRR data. Remote Sens. Rev. 1994, 10, 265-284.

69. Huete, A.R.; Liu, H.Q.; Batchily, K.; van Leeuwen, W. A comparison of vegetation indices over a global set of TM images for EOS-MODIS. Remote Sens. Environ. 1997, 59, 440-451.

70. Vincent, R.K.; Hunt, G.R. Infrared reflectance from mat surfaces. Appl. Opt. 1968, 7, 53-59.

71. Constantinou, G. The Geology and Genesis of The Sulphide Ores of Cyprus. PhD Thesis, University of London, London, UK, 1972.

72. Marsh, S.E.; McKeon, J.B. Integrated analysis of high-resolution field and airborne spectroradiometer data for alteration mapping. Econ. Geol. 1983, 78, 618-632. 
73. Morris, R.V.; Lauer, H.V.; Lawson, C.A.; Gibson, E.K.; Nace, G.A.; Stewart, C. Spectral and other physicochemical properties of submicron powders of hematite (Alpha- $\mathrm{Fe}_{2} \mathrm{O}_{3}$ ), maghemite (Gamma-Fe $\left.2 \mathrm{O}_{3}\right)$, magnetite $\left(\mathrm{Fe}_{3} \mathrm{O}_{4}\right)$, goethite (Alpha-Feooh), and lepidocrocite (Gamma-Feooh). J. Geophys. Res. 1985, 90, 3126-3144.

74. Bear, L.M. The Geology and Mineral Resources of the Akaki.-Lythrodondha Area; Geological Survey Department: Lefkosia, Cyprus, 1960.

75. Bishop, J.L.; Lane, M.D.; Dyar, M.D.; Brown, A.J. Reflectance and emission spectroscopy study of four groups of phyllosilicates: Smectites, kaolinite-serpentines, chlorites and micas. Clay Miner. 2008, 43, 35-54.

76. Rosenfield, G.H.; Fitzpatrick-Lins, K. A coefficient of agreement as a measure of thematic classification accuracy. Photogramm. Eng. Remote Sens. 1986, 52, 223-227.

77. Murphy, R.J.; Monteiro, S.T.; Schneider, S. Evaluating classification techniques for mapping vertical geology using field-based hyperspectral sensors. IEEE Trans. Geosci. Remote Sens. 2012, 50, 3066-3080.

78. Leverington, D.W. Discrimination of sedimentary lithologies using Hyperion and Landsat Thematic Mapper data: A case study at Melville Island, Canadian High Arctic. Int. J. Remote Sens. 2010, 31, 233-260.

(C) 2014 by the authors; licensee MDPI, Basel, Switzerland. This article is an open access article distributed under the terms and conditions of the Creative Commons Attribution license (http://creativecommons.org/licenses/by/4.0/). 